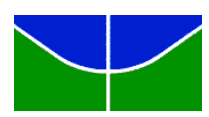

UNIVERSIDADE DE BRASÍLIA FACULDADE DE AGRONOMIA E MEDICINA VETERINÁRIA PROGRAMA DE PÓS-GRADUAÇÃO EM SAÚDE ANIMAL

\title{
VALORES DE REFERÊNCIA PARA TESTES DIAGNÓSTICOS OFTÁLMICOS EM ARARA CANINDÉ (Ara ararauna) E PAPAGAIO VERDADEIRO (Amazona aestiva).
}

\author{
Mário Sérgio Almeida Falcão
}

Publicação: 003/2015

Tese de Doutorado em Saúde Animal

Tese de Doutorado em Saúde Animal

Área de concentração: Clínica Médica e Cirurgia Animal

Linha de Pesquisa: Métodos de diagnóstico e tratamento de afecções dos animais domésticos e silvestres.

Brasília-DF

Dezembro/ 2015 


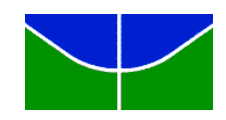

UNIVERSIDADE DE BRASÍLIA FACULDADE DE AGRONOMIA E MEDICINA VETERINÁRIA

PROGRAMA DE PÓS-GRADUAÇÃO EM SAÚDE ANIMAL

\title{
VALORES DE REFERÊNCIA PARA TESTES DIAGNÓSTICOS OFTÁLMICOS EM ARARA CANINDÉ (Ara ararauna) E PAPAGAIO VERDADEIRO (Amazona aestiva)
}

\author{
Mário Sérgio Almeida Falcão \\ Orientadora: Prof ${ }^{a}$. Dra. Paula Diniz Galera \\ Tese apresentada à Faculdade de \\ Agronomia e Medicina Veterinária da \\ Universidade de Brasília, para \\ obtenção do Título de Doutor em \\ Saúde Animal.
}

Brasília-DF

Dezembro/ 2015 


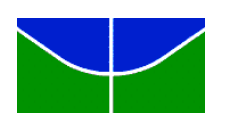

UNIVERSIDADE DE BRASÍLIA FACULDADE DE AGRONOMIA E MEDICINA VETERINÁRIA PROGRAMA DE PÓS-GRADUAÇÃO EM SAÚDE ANIMAL

\title{
VALORES DE REFERÊNCIA PARA TESTES DIAGNÓSTICOS OFTÁLMICOS EM ARARA CANINDÉ (Ara ararauna) E PAPAGAIO VERDADEIRO (Amazona aestiva).
}

\author{
Mário Sérgio Almeida Falcão \\ Orientadora: Prof ${ }^{\underline{a}}$ Dr$^{\text {a }}$ Paula Diniz Galera \\ Publicação: 003/2015 \\ Tese de Doutorado em Saúde Animal
}

\begin{abstract}
Área de concentração: Clínica Médica e Cirurgia Animal
Linha de Pesquisa: Métodos de diagnóstico e tratamento de afecções dos animais domésticos e silvestres.
\end{abstract}

Brasília-DF

Dezembro/ 2015 
Nome do au:or: Falcào, Mário Sérgio Almeida

Titulo: VALORES DE REFERENCIA PARA TESTES DIAGNOSTICOS OFTALMICOS EM ARARA CANINDÉ (Ara amarauna) E FAPAGAIO VERDADEIRO (Amazcna Eestiva)

Tese de Doutorado apresentada à Faculdade de Agronomia e Medicina Veterinára da Universidade de Bras lia

Aprowadoem

Banca Examinadora

Prof. Dra Paula Diniz Galera Julgameno Cupruadó
Instituçâo Universidade de Brasi ia-UnB Assinatura 1 jofleu

Prof. Marcelo Ismar Sartana Instituiçäo: Universidace de Brasitia-UnB Julgamento Aprovado Assir atura , Brest Prof. Rafael Verissima Monteiro Julgamento S/Lakno Assinatura Instituicão: Universidfog offmasilia-unB Prof. Francisco Ernesto M. Barnal Instituiçãs: Unì Julgamento f pronedo Ass natura

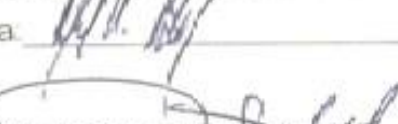
Prof Arderson Farias Julgamento

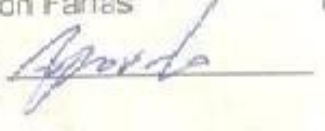
Instituicáa UPIS-DF Assinatura: 


\section{REFERÊNCIA BIBLIOGRÁFICA E CATALOGAÇÃO}

FALCÃO, M.S.A. VALORES DE REFERÊNCIA PARA TESTES DIAGNÓSTICOS OFTÁLMICOS EM ARARA CANINDÉ (Ara ararauna) E PAPAGAIO VERDADEIRO (Amazona aestiva). Brasília: Faculdade de Agronomia e Medicina Veterinária, Universidade de Brasília, 2015, 60 p. Tese de Doutorado.

Documento formal autorizando a reprodução desta tese de doutorado para empréstimo ou comercialização, exclusivamente para fins acadêmicos, foi passado pelo autor à Universidade de Brasília e acha-se arquivado na Secretaria do Programa. $O$ autor reserva para si os outros direitos autorais, de publicação. Nenhuma parte desta tese de doutorado pode ser reproduzida sem a autorização por escrito do autor. Citações são estimuladas, desde que citada a fonte.

Falcão, Mário Sérgio Almeida. VALORES DE REFERÊNCIA PARA TESTES DIAGNÓSTICOS OFTÁLMICOS EM ARARA CANINDÉ (Ara ararauna) E PAPAGAIO VERDADEIRO (Amazona aestiva). /Mário Sérgio Almeida Falcão. Brasília, 2015. Orientação Paula Diniz Galera - Brasília, 2015.

Tese de Doutorado - Universidade de Brasília/Faculdade de Agronomia e Medicina Veterinária, 2015.

1. Aves 2. Psitacídeos 3. Teste lacrimal de schirmer 4. Tonometria CDU

Agris/FAo 


\section{DEDICATÓRIA}

Dedico este trabalho a Deus, princípio e fim de tudo. Meu Senhor e meu Deus, te louvo e te agradeço por mais esta conquista, que sem Ti não seria possível. À minha família, que é tão especial para mim. 


\section{AGRADECIMENTOS}

Em primeiro lugar agradeço a Deus e a minha família.

À querida Professora Dra Paula Galera, que acompanhou toda a minha trajetória, me incentivando e apoiando desde o início.

Às colegas Mariana, Clarissa e Fernanda, que me auxiliaram na realização desse projeto, pois sem vocês seria impossível.

Ao Spazen por permitir a nossa entrada e a utilização dos animais sob sua responsabilidade.

Ao Serviço de Animais Silvestres da UnB em especial ao professor Rafael.

Ao Laboratório de Microbiologia da UnB, em especial a professora Simone e o Hudson.

A todos os amigos e funcionários do Hospital Veterinário da UnB.

A todos aqueles que se empenharam para que a conclusão desse trabalho fosse possível.

Meus sinceros Agradecimentos!!!!!!!!!!!!!!! 


\section{SUMÁRIO}

1 INTRODUÇÃO

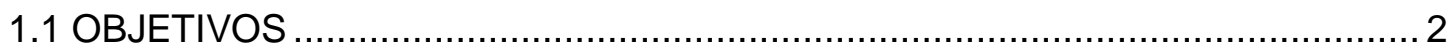

2 REFERENCIAL TEÓRICO....................................................................... 3

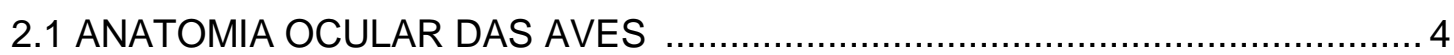

2.2 IMPORTÂNCIA DA AVALIAÇÃO OFTÁLMICA NAS AVES ............................ 13

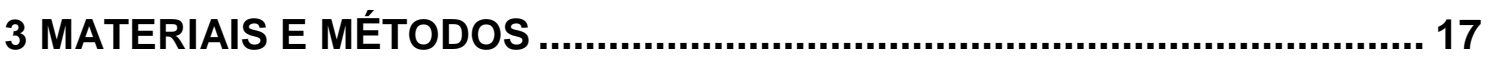

3.1 ASPECTOS ÉTICOS …...................................................................... 17

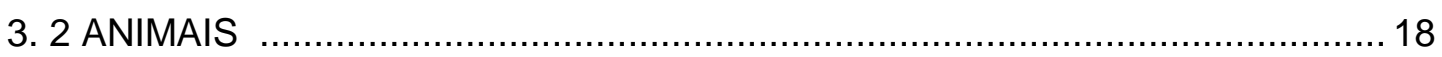

3. 3 ANESTESIA GERAL INALATÓRIA .......................................................... 19

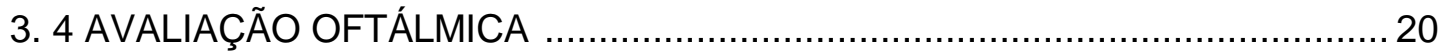

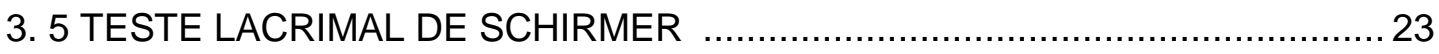

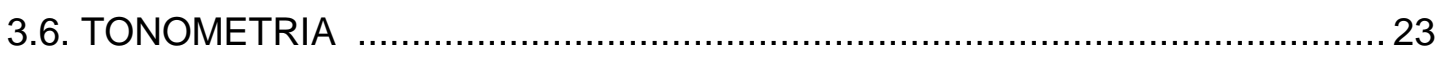

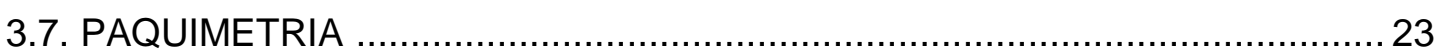

3.8. ANÁLISE MICROBIOLÓGICA …..................................................... 24

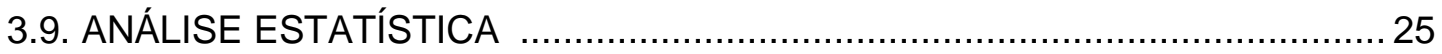

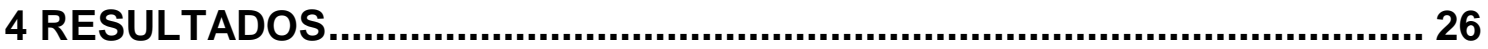

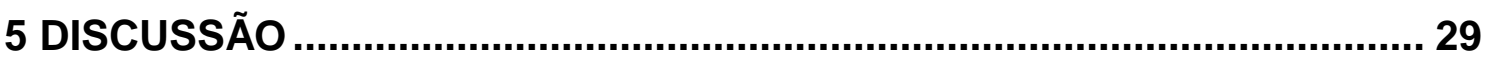

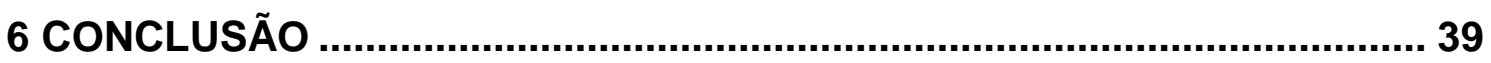

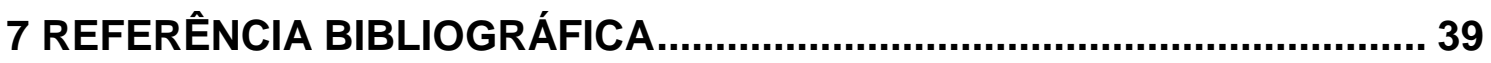




\section{LISTA DE TABELAS}

Tabela 1: Tabela 1- Valores do Teste Lacrimal de Schirmer, da Pressão Intraocular (PIO) antes e após anestesia e da fissura palpebral realizados em Ara ararauna $e$ expresso em média \pm desvio padrão.

Tabela 2: Tabela 2- Valores do Teste Lacrimal de Schirmer, da Pressão Intraocular (PIO) e da fissura palpebral realizados em Amazona aestiva e expresso em média \pm desvio padrão. 35

Tabela 3: Tabela 3- Frequência de microrganismos isolados em setenta olhos de Ara ararauna clinicamente e oftalmologicamente saudáveis. 


\section{LISTA DE FIGURAS}

Figura 1: Fita do TLS e TLSm inserida no terço médio do saco conjuntival da pálpebra inferior do olho direito de Ara ararauna (A) e Amazona aestiva (B).

Figura 2: Tonometria de rebote olho direito de Ara ararauna $(A)$ e olho esquerdo de Amazona aestiva (B).

Figura 3: Mensuração da fissura palpebral em olho direito de Ara ararauna (A) e de Amazona aestiva (B) com uso de paquímetro digital.

Figura 4: Coleta de amostra para cultura microbiológica realizada com auxílio de swab na região corneoconjuntival de olho esquerdo de uma Ara ararauna. 


\section{LISTA DE ABREVIATURA}

$\begin{array}{cc}\text { BO } & \text { Bulbo ocular } \\ \text { DP } & \text { Desvio padrão } \\ \text { EP } & \text { Erro padrão } \\ \text { HÁ } & \text { Humor aquoso } \\ \text { HV } & \text { Humor vítreo } \\ \text { MAX } & \text { Máximo } \\ \text { MIN } & \text { Mínimo } \\ \text { Mm } & \text { Milímetro } \\ \text { mm Hg } & \text { Milímetro de Mercúrio } \\ \text { mm/min } & \text { Milímetro por minuto } \\ \text { OD } & \text { Olho direito } \\ \text { OE } & \text { Olho esquerdo } \\ \text { PAQ } & \text { Paquimetria } \\ \text { PIO } & \text { Pressão intraocular } \\ \text { TLS } & \text { Teste lacrimal de Schirmer } \\ \text { TLSm } & \text { Teste lacrimal de Schirmer modificado }\end{array}$


RESUMO: Objetivou-se determinar os valores normais para testes oftálmicos diagnósticos selecionados para Arara Canindé e Papagaio Verdadeiro. Trinta e cinco Ara ararauna (70 olhos) e trinta Amazona aestiva (60 olhos), machos e fêmeas, provenientes de cativeiro credenciado no Distrito Federal, foram utilizadas. O teste de Lacrimal de Schirmer (TLS) médio foi de 7,65 \pm 4,57 OD e $6,57 \pm 4,37 \mathrm{~mm} / \mathrm{min}$ OE nas araras e o teste lacrimal de schirmer modificado (TLSm) nos papagaios foi de 6,37 $\pm 3,8$ OD e OE 6,50 $\pm 4,3 \mathrm{~mm} / \mathrm{min}$. $O$ diâmetro horizontal da fissura palpebral foi de 11,67 $\pm 0,078 \mathrm{~mm}$ OD e de 11,78 $\pm 0,095$ OE para araras, e de 10,09 $\pm 1,02 \mathrm{~mm}$ OD e de 10,17 $\pm 0,79$ OE nos papagaios. O TLS pelo teste Pearson apresentou correlação positiva com a medição da fissura palpebral para ambas as espécies estudadas. A pressão intraocular média foi de $11,34 \pm 2,53 \mathrm{mmHg}$ para OD anteriormente à anestesia e de 7,65 $\pm 2,37 \mathrm{mmHg}$ após a anestesia e no OE 11,65 $\pm 1,78$ e de 7,77 \pm $1,78 \mathrm{mmHg}$ nas araras, apresentado uma diferença estatística significativa entre as mensurações antes e após a anestesia. Nos papagaios, a PIO média foi de $6,31 \pm 1,7 \mathrm{mmHg}$ OD e de $6,13 \pm 1,97$ no OE. Em nosso estudo $84,15 \%$ das amostras analisadas são positivas para crescimento microbiológico, sendo que $56,10 \%$ apresentaram crescimento bacteriano, $10 \%$ fungos e 17 \%leveduras. Este estudo contribuiu para o estabelecimento de valores de referência para testes de diagnósticos oftálmicas importantes nas espécies estudadas.

PALAVRAS CHAVE: 1. Aves 2. Psitacídeos 3. Teste lacrimal de schirmer 4. Tonometria 
ABSTRACT:This study aimed to determine the normal values for selected ophthalmic diagnostic tests for Macaws (Ara ararauna) and Parrot (Amazon aestiva). Thirty-five Ara ararauna (70 eyes) and thirty Amazon aestiva (60 eyes), male and female, from captivity accredited in the Federal District, were used. The Schirmer Tear Test (STT) average was $7.65 \pm 4.57$ in the right eyes and $6.57 \pm 4.37 \mathrm{~mm} / \mathrm{min}$ in the left eyes on macaws and on the parrots STTm in the right eyes was $6.37 \pm 3.8$ and in the left eyes was $6.50 \pm 4.3 \mathrm{~mm} / \mathrm{min}$. The horizontal diameter of the eyelids rhyme was $11.67 \pm 0.078 \mathrm{~mm}$ in right eyes and $11.78 \pm 0.095$ in left eyes on macaws, and $10.09 \pm 1.02 \mathrm{~mm}$ in right eyes and $10.17 \pm 0.79$ in left eyes, in parrots . The STT by Pearson test showed a positive correlation with the measurement of palpebral fissure for both studied species. The average intraocular pressure was $11.34 \pm 2.53 \mathrm{~mm} \mathrm{Hg}$ for right eyes prior to anesthesia and $7.65 \pm 2.37 \mathrm{~mm}$ $\mathrm{Hg}$ after anesthesia and for left eyes was $11.65 \pm 1.78$, on the macaws, presented a statistically significant difference between the measurements before and after anesthesia. On parrots the average IOP was $6.31 \pm 1.7 \mathrm{~mm}$ $\mathrm{Hg}$ in the right eyes and $6.13 \pm 1.97$ in the left eyes. In our study $84.15 \%$ of samples are positive for microbial growth, of which $56.10 \%$ had bacterial growth, $10 \%$ fungi and $17 \%$ yeasts. This study contributed to the establishment of benchmarks for testing of important ophthalmic diagnoses in the studied species.

KEYWORDS: 1. Birds 2. Psittacidae 3. Schirmer Tear Test 4. Tonometry 


\section{1- INTRODUÇÃO}

As aves são consideradas animais com grande capacidade e acuidade visual, fatores esses importantes para reprodução, alimentação e voo (HART, 2002; REUTER, et al., 2011; WILLIAMS, 2012; RAUSCHER, et al., 2013).

A anatomia, morfologia e fisiologia ocular das aves possuem semelhanças aos dos mamíferos, entretanto, as especificidades encontradas podem influenciar diretamente a avaliação oftálmica nessas espécies. A semiotécnica oftálmica empregada em aves é a mesma utilizada para outras espécies animais, porém, as informações oftalmológicas diagnósticas são limitadas, dadas as particularidades inter e intra - espécies (RAUSCHER, et al., 2013), dificultando o diagnóstico de afecções oculares, mormente pela falta de parâmetros fisiológicos e pelas limitações do emprego de alguns dos métodos de diagnóstico utilizados em oftalmologia veterinária (HOLT, et al.,2006; ORIÁ, et al., 2015; SMITH; BARBON; FORBES, 2015).

É bem estabelecida a grande variabilidade entre espécies quanto aos resultados obtidos no teste lacrimal de Schirmer (TLS), na pressão intraocular (PIO), nos valores de espessura central da córnea (CCT), bem como da flora microbiana normal, especialmente quando se lida com animais exóticos ou silvestres. Todavia, a extrapolação de dados de uma espécie para outra deve ser evitada (MONTIANI-FERREIRA, et al., 2006; LYNCH; HOFFMAN; BLOCKER, 2007; JEONG, et al., 2007; SGORBINI, et al., 2008; KATO, 2014; BARSOTTI et al., 2013; GONZALEZ-ALONSO-ALEGRE, et al., 2015).

A literatura reporta estudos conduzidos em aves sobre o teste lacrimal de Schirmer, a tonometria e a flora conjuntival (HARRIS, 2008; KERN; COLITZ; 2013). Entretanto, dada a variação de valores encontrados na literatura para psitacídeos, faz-se necessária a descrição dos padrões dos referidos testes em espécies específicas, como araras e papagaios. 


\section{1- OBJETIVOS:}

Objetivou-se, com este estudo, estabelecer valores de referência para os principais testes oftálmicos em arara canindé (Ara ararauna) e papagaio verdadeiro (Amazona aestiva). 


\section{2-REFERENCIAL TEÓRICO}

\section{1- INTRODUÇÃO}

A ordem dos Psitaciformes inclui 78 gêneros e 332 espécies distribuídas mundialmente (GODOY, 2007). Destas, cerca de 80 ocorrem no Brasil, país considerado como o mais rico em variedade de psitacídeos (SICK, 2001; GODOY, 2007). A divisão das famílias pertencentes a essa ordem não é unânime entre autores, que a dividem em até três famílias diferentes, Loridae (lóris), Cacatuidae (cacatuas) e Psittacidae (periquitos, papagaios, araras, jandaias e maracanãs) (MACHADO, 2006), enquanto outros consideram a existência de uma única família, a Psittacidae, ou a divisão entre Psittacidae e Cacatuidae (GODOY, 2007).

Os psitacídeos são aves muito diversas, com variações em seus pesos, seus tamanhos e suas cores. Suas características específicas permitem o seu reconhecimento imediato, a exemplo do bico curto de base larga, adaptado para quebrar sementes e frutos, com a maxila particularmente móvel; cabeça grande e larga; região peri-oftálmica com ausência de penas; pescoço curto; pés zigodáctilos e pernas curtas (SICK, 2001; GODOY, 2007). A maioria das espécies não possui dimorfismo sexual (GODOY, 2007) e é monogâmica, podendo manter um mesmo companheiro por toda a vida (SICK, 2001; FRANCISCO \& MOREIRA, 2012).

A família Psittacidae possui o maior número de espécies ameaçadas dentre as famílias de aves, sendo que a perda de habitat e o tráfico de animais silvestres são as principais ameaças (FRANCISCO \& MOREIRA, 2012). Os psitacídeos tornam-se alvo em razão de suas penas coloridas e habilidade de imitar a fala humana, movimentando milhões de dólares por ano (SICK, 2001; GODOY, 2007), e a arara-canindé e o papagaio verdadeiro não são exceções (BIRDLIFE INTERNATIONAL, 2014).

A arara-canindé (Ara ararauna) pesa, em média, de 1 a 1,1 kg (GODOY, 2007), tendo comprimento do corpo de 80 a $86 \mathrm{~cm}$ (SICK, 2001; GWYNNE et al., 2010; AIZAWA, et al., 2013). Atinge sua maturidade sexual aos cinco anos (FRANCISCO \& MOREIRA, 2012) e constrói seus ninhos em troncos de 
árvores, com ninhadas de um a cinco ovos (BIANCHI, 1998) e tempo de incubação de 26 dias (BIANCHI, 1998; FRANCISCO \& MOREIRA, 2012), sempre com a presença de um dos pais no ninho (BIANCHI, 1998). Há relatos de que pode viver até 75 anos em cativeiro (GODOY, 2007). Caracteriza-se por apresentar penas de coloração azul na face dorsal e amarela na ventral e penas negras no pescoço e em pequenas fileiras na face (BIANCHI, 1998). Alimenta-se principalmente de semente e frutos, como os demais psitacídeos (GODOY, 2007), e é uma das espécies mais encontradas em residências e criadouros particulares de aves (BIANCHI, 1998).

A espécie Amazona aestiva, popularmente conhecida como papagaio verdadeiro, é uma das representantes brasileiras do gênero Amazona. Mede em média, de 35 a $37 \mathrm{~cm}$ de comprimento, e pesa cerca de $400 \mathrm{~g}$. Atinge a maturidade sexual aos cinco anos, assim como as araras. Reproduz-se normalmente em buracos de rochas ou em barrancos, e os filhotes permanecem no ninho por cerca de dois meses. Os indivíduos desta espécie apresentam coloração predominantemente verde, cabeça amarela com fronte azul, pés e bicos pretos. A alimentação é baseada em sementes e frutos (FORSHAW, 2010, CHRISTOFOLETTI, 2014). Dada a sua habilidade à fala $\mathrm{e}$ a interação com o ser humano, ainda hoje é procurado para ser domesticado pelo homem (GODOY, 2007)

\section{2- ANATOMIA OCULAR DAS AVES}

Nas aves a proporção de seus bulbos oculares em relação ao crânio é muito grande (DAVIDSON, 1997; LABELLE, et al., 2012), o que é vantajoso para as espécies que dependem da sua capacidade de interpretar e responder ao seu ambiente visual (BROOKE; HANLEY; LAUGHLIN, 1999; BURTON, 2008), porém torna os olhos mais suscetíveis aos traumas oculares (BECKWITH-COHEN, et al., 2015). Os olhos das aves variam em tamanho e forma (LIMA, et al., 2009), e na maior parte dos casos, o segmento posterior do olho é desproporcionalmente maior do que o segmento anterior (MACHADO; SCHIMIDT; MONTIANI-FERREIRA, 2006). 
O formato do bulbo ocular das aves pode ser classificado como plano, com um eixo anteroposterior curto (por exemplo, aves domésticas); globoso (por exemplo, aves de rapina diurnas); ou tubular (típicos de corujas) (WILLIS; WILKIE, 1999; BAYON; ALMELA; TALAVERA, 2007). A maior parte das aves, incluindo os passeriformes e psitacídeos, tem um bulbo ocular achatado no sentido anteroposterior (MACHADO; SCHIMIDT; MONTIANI-FERREIRA, 2006), a exemplo das araras e papagaios.

\subsection{1- Órbita}

A órbita óssea se desenvolve embriologicamente a partir das células mesenquimais em torno da vesícula óptica (SEIFERT; JACOB; JACOB, 1993). Cada cavidade orbital, essencialmente, é concebida para a acomodação e apresentação dos bulbos oculares. Contém músculos, vasos, nervos, aparelho lacrimal e um tecido adiposo (DARWISH, et al., 2006; MACHADO; SCHIMIDT; MONTIANI-FERREIRA, 2006). A órbita é também uma região anatômica de interesse clínico e cirúrgico para muitas disciplinas médicas, como oftalmologia veterinária, cirurgia oral, cirurgia maxilofacial e neurocirurgia (MACHADO; SCHIMIDT; MONTIANI-FERREIRA, 2006).

A órbita das aves é formada pela contribuição do osso frontal, préfrontal, esfenóide, etimóide, palatino, ossos quadrados e o arco julgal (PAULMURPHY,et al., 1989; DARWISH, et al., 2006; JONES; PIERCE; WARD, 2007), e pode ser aberta ou fechada (WILLIAMS, 2012). Em Ara ararauna a órbita é incompleta ventralmente (MACHADO; SCHIMIDT; MONTIANIFERREIRA, 2006) e em Amazon parrots, é fechada, tidas (ambas?) como órbita completa (KRAUTWALD-JUNGHANNS; KOSTKA; DORSCH, 1998). Nas aves muitos dos elementos da órbita óssea são pneumatizados, o que aumenta a sua susceptibilidade durante um trauma cirúrgico (MACHADO; SCHIMIDT; MONTIANI-FERREIRA, 2006; WILLIAMS, 2012; SAMUELSON, 2013).

As duas órbitas ósseas são separadas por uma placa fina de osso, o septo interorbital (PAUL-MURPHY, et al., 1990). No aspecto dorsal, o osso frontal forma a margem supraorbital. Em Psitaciformes, este local apresenta um osso chamado arco suborbital, que delimita a órbita ocular ventralmente 
(BAYON, ALMELA, TALAVERA; 2007). A margem rostral da órbita é criada pelo osso pré-frontal. A órbita óssea completa de psitacídeos é uma estrutura aparentemente estável, não sendo comumente acometida por fraturas (PAULMURPHY, et al., 1990).

A característica mais importante da órbita é a proximidade do bulbo ocular com o divertículo infraorbital do seio infraorbital. $O$ aumento deste divertículo em quadros de sinusite ou outras doenças do trato respiratório superior, por sua proximidade à órbita, pode acarretar uma série de condições de edema periorbital, compressão orbital, conjuntivite e em alguns casos, exoftalmia, podendo até mesmo se estender internamente, levando a quadros de inflamações intraoculares (WILLIS \& WILKIE, 1999; WILLIAMS, 2012).

\subsection{2- Pálpebras e Anexos Oculares}

As pálpebras das aves são finas e, por vezes, transparentes (WILLIS \& WILKIE, 1999). São divididas em pálpebra superior, inferior e membrana nictitante. A pálpebra inferior, geralmente contém uma porção fibroelástica possui maior mobilidade, sendo a responsável por recobrir a maior parte do bulbo ocular durante o ato de piscar (WILLIS; WILKIE, 1999; BAYON; ALMELA; TALAVERA, 2007; KERN; COLITZ; 2013). A glândula de Meibômio é ausente nas aves e a conjuntiva é morfologicamente semelhante as dos mamíferos (KERN; COLITZ; 2013).

A membrana nictitante é bem desenvolvida e ativamente móvel na maior parte das espécies aviárias (DAVIDSON, 1997; JONES; PIERCE; WARD, 2007). Está localizada a partir do aspecto dorso-nasal do olho sobre a córnea, e é movimentada pela contratura do músculo piramidal, que se origina a partir da porção posterior da esclera (DAVIDSON, 1997; WYGNANSKI-JAFFE; et al., 2007). Além da glândula lacrimal, temos a glândula de Harder, que não faz parte da membrana nictitante nessas espécies (SIMOVA - CURD, et al., 2009).

A glândula lacrimal está inserida na parte ventro-temporal do bulbo ocular, não sendo encontrada em algumas espécies como Strigiformes (KORBEL; LEITENSTORFER, 1998). Já a glândula Harderiana fica localizada na região retrobulbar, adjacente à esclera posterior, próxima à base da terceira 
pálpebra, porém externamente a ela (WILLIS \& WILKIE, 1999). A glândula Harderiana é a principal fonte de lágrimas em aves (WILLIAMS, 2012). Um ducto se desloca a partir desta glândula e se abre dentro do saco conjuntival entre o bulbo ocular e a terceira pálpebra. Duas punctas lacrimais drenam as secreções para o ducto nasolacrimal (SAMUELSON, 2013) e consequentemente para dentro da cavidade nasal (BURNS; MAXWELL, 1974).

Os seios paranasais do crânio aviário, em particular o seio infraorbital, são comumente envolvidos por doenças das vias respiratórias superiores e em razão da sua proximidade com a órbita, podendo ser acometidos pela doença orbital e ocular secundária (WILLIS; WILKIE, 1999).

A movimentação ocular está intimamente relacionada à contração dos músculos extraoculares (WYGNANSKI-JAFFE; et al., 2007). Nas aves esses músculos são pobremente desenvolvidos, tornando o movimento ocular limitado, o que é compensado pelo movimento da cabeça (DARWISH, et al., 2006; MARTIN; SHAW, 2010). Os músculos extraoculares presentes nas aves são os quatro retos (medial, lateral, dorsal e ventral), os dois oblíquos (dorsal e ventral), estando ausente o músculo retrator do bulbo, que é substituído nas aves pelo músculo quadrado e piramidal (JONES; PIERCE; WARD, 2007; KERN; COLITZ, 2013).

\subsection{3- Túnica Fibrosa (Córnea e Esclera)}

A túnica fibrosa é composta pela córnea anteriormente e a esclera posteriormente. Histologicamente é semelhante à de outros vertebrados. A córnea aviária é transparente, avascular e possui cinco camadas (JONES; PIERCE; WARD, 2007; WILLIAM, 2012; NAUTSCHER et al., 2015). O epitélio corneano que é seguido por uma segunda camada denominada de Bowman's que é bem desenvolvida (DAVIDSON, 1997) e acelular, funcionando com um limitante para o epitélio anteriormente localizado. A terceira camada é o estroma, que representa cerca de $90 \%$ da espessura corneana total. A quarta camada é a membrana de Descement ( e a quinta camada o endotélio, que em conjunto com o epitélio são os responsáveis pelo estado de deturgecência 
corneana, ou seja, a sua desidratação (JONES; PIERCE; WARD, 2007, et al., 2007).

A córnea desempenha funções importantes como: funcionar como barreira para o conteúdo intraocular, refrata a luz por meio de sua curvatura e transmitir a luz por sua transparência. A córnea é mantida úmida e nutrida não só pela glândula lacrimal, mas também pelas secreções lacrimais da glândula Harderiana (KERN, et al., 1996; BARSOTTI, et al., 2013) e intraocularmente pelo humor aquoso (SAMUELSON, 2013).

A esclera é uma estrutura resistente nas aves, sendo capaz de manter o formato do bulbo ocular, preservando de mudanças relacionadas a pressões internas e externas (FRANZ-ODENDAAL, 2005; WYGNANSKI-JAFFE, et al., 2007; LIMA, et al., 2009). Nas aves é constituído por ossículos e cartilagem hialina. A cartilagem se estende até 0 ponto dos ossículos esclerais posteriormente ao limbo. O número de ossículos esclerais pode variar entre as espécies aviárias, estando entre 10 e 18 (PAUL-MURPHY, et al., 1990; DAVIDSON, 1997) entretanto, a maior parte das espécies aviárias têm entre 14 e 15 ossículos (JONES; PIERCE; WARD, 2007, et al., 2007). Porém, um estudo realizado em psitacídeos sugere que as araras possuem entre 12-13 e os papagaios entre 11-12 ossículos (LIMA, et al., 2009).

A primeira função dos ossículos é a de fornecer proteção e suporte ao bulbo ocular durante as deformações que surgem no voo e/ou no mergulho, de acordo com cada característica da ave. Como servem de local para a inserção do músculo ciliar estriado, sugere-se que uma segunda função importante dos ossículos seria a participação no processo de acomodação visual (JONES; PIERCE; WARD, 2007; LIMA, et al., 2009).

\subsection{4- Túnica Vascular}

A coróide em conjunto com a íris e o corpo ciliar forma a úvea, um dos tecidos mais vascularizados do corpo (STEFANO; MUGNAINI, 1997; GUM; MacKAY, 2014). A pupila é uma abertura (diafragma) que delimita anatomicamente duas regiões oculares, criando, assim, uma região denominada de câmara anterior e outra de câmara posterior, sendo a 
comunicação entre as duas por meio dela (JONES; PIERCE; WARD, 2007; SAMUELSON, 2013).

A íris é composta por numerosos vasos sanguíneos, fibroblastos, nervos, colágeno, células epiteliais, além de um extenso componente muscular. Ela regula a quantidade de luz que entra no segmento posterior do olho pelo seu mecanismo de contração ou dilatação pupilar. O componente muscular é primariamente constituído por músculo estriado, o que fornece um mecanismo de controle voluntário. A presença do músculo estriado favorece o controle rápido do tamanho pupilar e da sua consequente contrição (GUM; MacKAY, 2014). Essa constituição muscular faz com que agentes midriáticos tradicionais não forneçam dilatação pupilar nas aves, por não agirem sobre os músculos estriados iridianos. Assim, um agente de bloqueio neuromuscular de ação periférica é necessário para iniciar midríase e facilitar o exame da retina (LOERZEL, et al., 2002; BAYON, ALMELA; TALAVERA, 2007).

A coloração iridiana é resultado da quantidade de pigmentação, dos tipos de pigmentação e do grau de vascularização. As purinas e pteridinas foram identificadas como os principais pigmentos carotenóides iridianos e, apesar de estarem presentes em menor extensão nas aves, também desempenham um papel na pigmentação iridiana dessas espécies (JONES; PIERCE; WARD, 2007).

O corpo ciliar desempenha um papel importante no funcionamento intraocular. Ele é responsável por fornecer o suprimento sanguíneo e nervoso do segmento anterior, controlar o processo de acomodação visual, constitui a barreira hemato-aquosa e estruturalmente constitui a via de saída não convencional de drenagem do humor aquoso (GUM; MACKAY, 2014). Em aves o corpo ciliar é composto por dois distintos grupos musculares, um anterior e outro posterior, o músculo de Crampton e o músculo de Brücke, respectivamente. Esses músculos são estriados, em contraste com o músculo liso do músculo ciliar dos mamíferos. (JONES; PIERCE; WARD, 2007; GUM; MACKAY, 2014).

O humor aquoso (HA) é um fluido transparente que ocupa a câmara anterior (formada pelo espaço entre a córnea e a íris) e a posterior (formada pelo espaço entre a íris e capsula anterior da lente). É produzido pelo epitélio 
não pigmentar do corpo ciliar por meio de três processos fisiológicos: difusão, ultrafiltração e secreção ativa. Após a produção, o HA adentra à câmara posterior e, por uma corrente de convecção térmica se desloca para câmara anterior, onde é drenado pelas vias convencional (ângulo iridocorneano) e não convencional (via uveoescleral) de drenagem do humor aquoso. Em aves o ângulo iridocorneano é bem desenvolvido e possui dois canais de drenagem anulares. Esse equilíbrio entre a produção e a drenagem do humor aquoso é o que gera a pressão intraocular (PIO) (KERN; COLITZ, 2013; DAVIS, et al., 2014; GUM; MACKAY, 2014).

O humor aquoso desempenha algumas funções importantes no olho, como a nutrição das estruturas intraoculares avasculares, a córnea e a lente, e auxilia na remoção de produtos metabólicos. É importante para a manutenção da propriedade óptica do bulbo ocular, proporcionando transparência e apropriado poder refrativo entre a córnea e a lente (SAMUELSON, 2013; DAVIS, et al., 2014).

A coróide é composta por tecido conjuntivo pigmentado e de pequenos vasos. É uma importante fonte de oxigênio e nutrientes para a retina e dissipa o calor produzido a partir da absorção da luz pelos fotorreceptores (STEFANO; MUGNAINI, 1997). A coróide retiniana pode ser dividida em cinco camadas. A primeira e mais externa é a lâmina supracoroídea, que é composta por tecido conjuntivo elástico e pigmentado que forma a transição entre a coróide e a esclera. A segunda camada, a pericoroídea, consiste em fibras de feixes musculares estriados e não estriados e fibras de tecido conjuntivo. A lâmina vascular é a terceira camada e consiste predominantemente de artérias. A lâmina coriocapilar é a quarta camada e ajuda a fornecer oxigênio para a retina. A lâmina basal é uma membrana basal fina que separa os coriocapilares do pigmentado do epitélio da retina sendo considerada a quinta camada (JONES; PIERCE; WARD, 2007).

\subsection{5- Lente}

A lente é uma estrutura macia, flexível e de forma variável (KERN; COLITZ, 2014). É avascular e transparente e sua finalidade principal é refratar 
e concentrar os raios de luz sobre os fotorreceptores da retina. A lente aviária tem muita variação entre as espécies que reflete diferenças no poder refrativo, no amplo poder acomodatício e interferem nos campos visuais (BROOKS, 1997).

A anatomia da lente das aves possui particularidades em relação à de mamíferos (JONES; PIERCE; WARD, 2007). Trata-se de um corpo central, constituído de córtex e núcleo, e a presença de uma almofada anular (BROOKS, 1997; JONES; PIERCE; WARD, 2007). A lente é delimitada pela cápsula anterior e posterior, ambas elásticas. Pode, assim, ter suas regiões divididas em capsular, subcapsular, cortical e nuclear e subdivididas em polo posterior e polo anterior, além de regiões equatoriais (BROOKS, 1997).

A almofada anular está separada do núcleo central por uma câmara cheia de líquido, a vesícula lenticular. Esta disposição anatômica pode ser um mecanismo hidrostático para absorver à pressão exercida pelo músculo ciliar sobre o núcleo central e facilitar o mecanismo de acomodação ocular (KERN; COLITZ, 2013).

A lente das aves, juntamente com a córnea, serve para refratar a luz. A lente foca a luz sobre a superfície da retina, criando uma imagem. O que decorre de sua transparência, sua ausência de vasos e suas propriedades de acomodação. A lente é mantida na sua posição pelos ligamentos zonulares e pelas fibras vítreas, que se ligam aos processos zonulares ciliares e a almofada anular no equador lenticular sob o apoio da íris (JONES; PIERCE; WARD, 2007). Existe uma relação direta entre o tamanho da almofada e o grau de habilidade acomodativa. Uma vez que a taxa de desenvolvimento da fibra da lente é mais lenta do que a de mamíferos, as aves são capazes de manter uma lente mais macia e maleável, necessária para acomodação rápida por mais tempo (BROOKS, 1997; JONES; PIERCE; WARD, 2007).

\subsection{6- Segmento posterior e Túnica nervosa}

O segmento posterior do bulbo ocular é preenchido pelo humor vítreo (HV). O HV é uma substância gelatinosa, transparente, que transmite a luz, fornece estrutura para o bulbo ocular e ajuda a manter a posição normal da 
retina. Ocupa aproximadamente $80 \%$ do bulbo ocular e é composto por $99 \%$ de água e $1 \%$ de ácido hialurónico. 0 vítreo está firmemente ligado à cápsula posterior da lente, e a fossa patelar adjacente à face posterior da lente (JONES; PIERCE; WARD, 2007).

As retinas de todos os vertebrados são similares, entretanto, a anatomia do fundo ocular das aves possui algumas características únicas (RAUSCHER, et al., 2013). As retinas das aves são cones dominantes, com poucas exceções relacionadas às aves noturnas. Algumas espécies de aves têm uma ou duas regiões ricas em cones e livres de bastonetes dentro de sua retina. Essas áreas são chamadas fóveas e são usadas para perceber um matiz de cor de alta resolução e auxiliar na fixação da visão binocular, aumentando a percepção de profundidade. As fóveas são depressões na retina que contém apenas cones e nas quais as imagens são focadas para a obtenção de um aumento da acuidade visual (RAUSCHER, et al., 2013; McKIBBIN, et al., 2014).

As retinas são avasculares, mas possuem uma estrutura nutritiva especializada, o pécten (HIRSCH, 1982; RAUSCHER, et al., 2013; McKIBBIN, et al., 2014). O pécten é uma estrutura não sensorial, altamente pigmentada, de formato variável. Estende-se do nervo óptico para dentro da câmara vítrea. Realiza a nutrição do interior do olho por difusão por meio do corpo vítreo, onde esse mecanismo é fornecido pelas oscilações do pécten durante o movimento ocular. O pécten também fornece uma concentração de oxigênio para as funções retinianas no equilíbrio ácido - básico e na manutenção da temperatura intraocular constante. Os formatos e o número de pregas (dobras) do pécten variam entre as aves noturnas e diurnas. Apesar da variação de tamanho e forma entre as espécies, em geral, as aves diurnas tem um pécten maior, com mais dobras do que as espécies noturnas. A atividade das aves pode também desempenhar um fator de variabilidade do pécten $(\mathrm{HIRSCH}, 1982$; RAUSCHER, et al., 2013; McKIBBIN, et al., 2014). 


\section{3- IMPORTÂNCIA DA AVALIAÇÃO OFTÁLMICA NAS AVES}

A acuidade e o desempenho visual são de grande importância para as aves, especialmente para espécies rapinantes e selvagens. A oftalmologia aviária é um campo em crescimento da medicina aviária. Isso resulta de avanços na criação de animais exóticos; na proteção de animais selvagens; na criação orientada de animais, prezando pelo bem-estar em zoológicos e, adicionalmente, no controle da saúde dos animais reprodutores, especialmente das aves de rapina. Animais dessas categorias são apresentados ao veterinário de aves com uma prevalência de doenças oculares diferentes das demais e estão sujeitos a distintos procedimentos, inclusive em decorrência de critérios financeiros (RAUSCHER, 2013).

Clínicos de aves são frequentemente confrontados com doenças oculares de seus pacientes (BUYUKMIHCI; MURPHY; SCHULZ, 1988), o que pode ser o resultado de doenças sistêmicas infecciosas (bacterianas, micóticas, viral), doenças não infecciosas (traumas, neoplasias, nutricionais, tóxicas) ou de etiologia desconhecida. Distúrbios oculares do segmento posterior em aves selvagens são frequentes, como as hemorragias relacionadas ao trauma, edema e descolamento retiniano (RAUSCHER, 2013).

As lesões oculares e palpebrais são um achado comum em aves (FERNANDEZ; DUBIELZIG, 2014; BECKWITH-COHEN, et al., 2015), e o trauma ocular e periocular representam cerca de $30 \%$ das lesões nos animais que sofreram traumas. As lesões traumáticas incluem colisão com janelas, automóveis, árvores e construções (MARTIN, 2007; MARTIN; SHAW, 2010; SERUCA, et al., 2011).

Em grandes psitacídeos as doenças periorbitais secundárias às infecções do trato respiratório superior, como rinite e sinusite crônica, também são uma apresentação frequente (HVENEGAARD, et al., 2009).

Agentes causadores de ceratoconjuntivite em papagaios incluem: bactéria, clamídia, micoplasma, virais, parasitárias, doenças fúngicas e deficiência de vitamina A (TSAI, et al., 1993). Destas, as infecções bacterianas são as mais frequentes e as fúngicas, as menos comuns (HOPPES, et al.,2000; RAUSCHER, et al., 2013). 
Alguns estudos descrevem a anatomia ocular e os resultados de testes de diagnósticos selecionados, com foco em aves de rapina, psitacídeos e pinguins. Porém, o conhecimento limitado de achados de exame ocular em outras espécies aviárias pode resultar na incapacidade de identificar afecções oculares nestes animais (KERN; COLITZ, 2013; BECKWITH- COHEN, et al., 2015).

Doenças oculares subdiagnosticadas têm 0 potencial de afetar negativamente a qualidade de vida, causando afecções que podem diminuir até mesmo a expectativa de vida dessas aves (MEEKINS, et al., 2015).

A avaliação oftálmica em aves segue os princípios da semiotécnica oftalmológica de rotina, todavia, alguns testes possuem limitações em sua aplicação em virtude do tamanho dos olhos, da ausência de dados e de restrições financeiras (WILLIS; WILKIE, 2007). O uso de biomicroscopia com lâmpada em fenda é importante e permite a avaliação de lesões do segmento anterior, anexos oculares e até mesmo avaliação do segmento posterior com a utilização de uma lente de + $30 \mathrm{D}$ (Dioptrias). A oftalmoscopia direta, por vezes, torna-se complicada em razão da pupila pequena em muitas espécies e associada à dificuldade de dilatação pupilar. Porém, com cuidado e tempo, um exame detalhado do fundo de olho pode ser realizado (WILLIAMS, 2012).

\subsection{1- Teste Lacrimal de Schirmer}

Diante da mencionada dificuldade de realizar um exame oftálmico completo em aves, testes auxiliares tornam-se ainda mais valiosos. No entanto, para que se tornem adequados precisam ser modificados em razão do tamanho e da variedade dos olhos. Um exemplo disso é o teste lacrimal de Schirmer (TLS), utilizado para avaliação da produção lacrimal. O TLS é uma fita padronizada, com cinco milímetros de diâmetro, graduada a cada cinco milímetros de comprimento, mensurando até trinta milímetros de comprimento (SILVA, et al., 2013).

Deve ser colocada na pálpebra inferior, no terço médio, aguardando-se por um minuto. O TLS possui tamanho inadequado para a inserção em muitos dos olhos aviários. Outrossim, ainda que pudesse ser posicionado na pálpebra 
inferior a quantidade de lágrima produzida por essas aves, no tempo referido de um minuto, não seria suficiente para alcançar um comprimento mensurável de umectação na fita. Uma das alternativas seria o corte da fita ao meio, o que, no entanto, em razão da insuficiência de dados, não seria de todo seguro, pois não se sabe, ao certo, qual seria a produção lacrimal normal de determinadas espécies de aves em meia fita. Para a referida avaliação lacrimal, poder-se-ia utilizar o teste vermelho fenol, que é uma fita de algodão impregnada por um corante amarelo que em contato com a lágrima fica vermelho. Uma vantagem na utilização do vermelho fenol é que a fita de algodão pode ser deixada por apenas quinze segundos (WILLIAMS, 2012). Ambos os testes são comumente utilizados em humanos, animais domésticos (cães, gatos, cavalos, porcos, ferrets) (LANGE, et al., 2012) e aves (HOLT; ROSENTHAL; SHOFER, 2006; MEEKINS, et al., 2015).

Existem relatos do teste lacrimal de Schirmer e do teste lacrimal de Schirmer modificado para aves. Em um estudo conduzido por Korbel \& Leitenstorfer (1998) utilizando 255 aves, de 42 espécies diferentes, foram apresentados valores para o TLS em psitacídeos. A referida avaliação lacrimal obteve como resultado 3,2-7,5 $\mathrm{mm} / \mathrm{min}$ sem anestesia tópica e 1,7-4,5mm $/ \mathrm{min}$ com anestesia tópica. Em Falconiformes 4,1-14,44mm/min sem anestesia e 2$4,2 \mathrm{~mm} / \mathrm{min}$ com anestesia tópica.

\subsection{2- Tonometria}

A avaliação da estimativa da pressão intraocular em animais com doenças oculares, tais como uveíte e glaucoma, é importante procedimento diagnóstico oftálmico (JEONG, et al., 2007; KATO, 2014), pois, embora o glaucoma primário raramente seja documentado em aves (DAVIS, et al., 2014), as doenças causadas por traumas oculares são frequentes (DAVIDSON, 1997; KUHN, et al., 2013).

A mensuração da pressão intraocular realizada de forma não invasiva é realizada por meio dos tonômetros (SPIESSEN, et al., 2015). Os tonômetros de aplanação e os de rebote são os equipamentos mais utilizados em Medicina 
Veterinária, tendo sido esse último introduzido mais recentemente (REUTER, et al., 2010; SPIESSEN, et al., 2015).

Embora a tonometria de aplanação seja considerada um método preciso e confiável para estimar a PIO em animais, em olhos com diâmetro corneano inferior a 3 milímetros, a mensuração pode não ser possível (BARSOTTI, et al., 2013; RUSANEN, et al., 2010). Já no caso do tonômetro de rebote, as curvas de calibração interna foram desenvolvidas pelo fabricante para a aferição da pressão intraocular em animais de olhos pequenos (KNOLLIGER, et al, 2005; JOHNSON, et al., 2008; MERCADO, et al., 2010). Outro fator positivo é a dispensabilidade do uso de anestesia ocular tópica (RUSANEN, et al., 2010). Registre-se que valores de tonometria com o uso de tonômetro de aplanação são descritos para aves de rapina (11-16 mmHg) e para psitacídeos (20-25 $\mathrm{mmHg}$ ). Um estudo realizado em 31 aves de rapina com o uso do tonômetro de rebote obteve valor médio de $9 \mathrm{mmHg}$, e em grandes aves valores próximos a $40 \mathrm{mmHg}$ (BAYON; ALMELA; TALAVERA, 2007).

\subsection{3- Cultura microbiológica}

Relatos de blefarite e dermatite secundária à infecção em aves de companhia são frequentes, comparados aos de aves de rapina (ABRAMS, et al., 2001). As bactérias e os vírus são as causas infecciosas mais comumente diagnosticadas de conjuntivite em aves (KORBEL, 2011).

Conjuntivite bacteriana pode ser uma extensão de infecção do sistema respiratório superior ou secundária a uma infecção oportunista pela flora normal conjuntival. Recomenda-se uma análise aprofundada da região coanal e seios periorbital (WILLIS; WILKIE, 1999; BAYON; TAVALERA, 2007).

As bactérias mais comumente envolvidas nos quadros de conjuntivite incluem Pseudomonas, Staphylococcus, Pasteurella, Citrobacter, Escherichia coli, Klebsiella. e Mycoplasma spp. (HOLMBERG, 2008). 


\section{3- MATERIAIS E MÉTODOS}

\section{1- ASPECTOS ÉTICOS}

O estudo foi submetido e aprovado pelo Comitê de Ética e Uso de Animais da Universidade de Brasília (protocolo n44763/2014) e realizado de acordo com os princípios éticos da ARVO (Statement for the Use of Animals in Ophthalmic and Vision Research).

\section{2- ANIMAIS}

Avaliaram-se Araras Canindé e papagaios verdadeiros. As aves eram adultas, de sexo indeterminado e sem problemas clínicos ou oftálmicos. Todos os animais eram oriundos de cativeiro credenciado pelo IBAMA (Instituto Brasileiro do Meio Ambiente e dos Recursos Naturais Renováveis) denominado Spazen Arte Vivenda, sediado no Distrito Federal, região Centro-Oeste do Brasil. As aves utilizadas serão reintroduzidas à natureza e são mantidas em criadouros conservacionistas.

Para inclusão no experimento, foram avaliadas 38 araras e 35 papagaios. Todos os animais foram submetidos à avaliação clínica com mensurações da frequência cardíaca e respiratória, temperatura, peso e realização da auscultação cardíaca e pulmonar. Ato contínuo, foi realizada coleta de sangue para avaliação hematológica (hemograma), seguida por inspeção oftálmica, com realização de biomicroscopia com lâmpada em fenda, para determinação da higidez ocular. Animais que apresentaram alterações oculares visualmente detectáveis ou alterações clínicas foram posteriormente excluídos do estudo.

Das aves avaliadas, no grupo das araras, três foram descartadas sendo que, dessas, uma apresentava alteração ocular em um dos olhos e duas apresentavam alterações respiratórias. Nos papagaios avaliados, cinco animais eram de espécie diferente a do papagaio verdadeiro e, portanto, não foram incluídos nesse estudo.

As coletas de dados nas araras foram realizadas de setembro a dezembro de 2014, sendo realizadas duas vezes por semana, com horário de 
início as $08 \mathrm{~h} 30 \mathrm{~min}$ e término às $16 \mathrm{~h} 30 \mathrm{~min}$, com média de quatro animais por dia de avaliação. As mensurações nos papagaios foram realizadas entre setembro e outubro de 2015 , sendo realizada uma vez por semana das 08h30min min às $16 \mathrm{~h} 30 \mathrm{~min}$, com média de seis animais por dia de avaliação.

Para a coleta de dados os animais eram capturados com ajuda de puçá nos recintos e transportados para sala de exame que foi previamente preparada. A sala era localizada na mesma propriedade onde residiam os animais. A distância percorrida com os animais do local de captura a sala de exames era curta de aproximadamente $500 \mathrm{~m}$. As araras eram capturadas individualmente e transportados em sacos individuais. Ao chegar à sala de exames eram mantidas em repouso por um mínimo de cinco minutos a fim de minimizar o estresse oriundo da captura antes de serem novamente manipuladas. O procedimento com os papagaios foi o mesmo, porém os recintos desses animais eram mais próximos da sala de exame.

A sala de exame possuía ventilação adequada, pia em aço inoxidável, mesa de procedimento que era preparada para manusear as aves e realizar os testes propostos.

Previamente a condução da pesquisa, realizou-se um estudo piloto com duas araras e dois papagaios a fim de se verificar a viabilidade do estudo, o tempo transcorrido entre os procedimentos e a manipulação dos animais. Os papagaios permitiram a realização dos testes oftálmicos mediante contenção física. Já as araras apresentaram vocalização e agitação intensas, motivo que determinou a utilização de contenção química destes animais durante a pesquisa, além da preocupação em se evitar acidentes e minimizar o estresse.

\section{3- ANESTESIA GERAL INALATÓRIA}

Para a realização do procedimento anestésico, as araras foram submetidas a jejum alimentar prévio de oito horas no dia anterior a coleta dos dados e jejum hídrico de duas horas no dia de realização do experimento (MASSONE, 2003). As araras eram contidas no criadouro com uso de puçá e transferidas para a sala de exame em saco próprio para uso em aves. Ao chegar a sala de exame eram mantidas em repouso por pelo menos 5 minutos, 
antes de nova manipulação, como supracitado, com a intenção de minimizar o estresse oriundo da captura e a possível interferência com o procedimento anestésico. Após o descanso pré-determinado as aves eram contidas fisicamente em posição vertical, posicionando-se os dedos atrás da cabeça e sobre o bico.

Para a indução anestésica, optou-se por induzir a anestesia com auxílio de uma máscara com isofluorano com fluxo diluente de oxigênio a $100 \%$. A cada trinta segundos, 0,5 de $\mathrm{V} \%$ de anestésico era aumentado, até obtenção de plano anestésico. As aves entraram em plano, em média, com quatro minutos após indução e a concentração média correspondeu a 3,5V\%.

As aves foram então mantidas em anestesia geral inalatória (HP slim ${ }^{\circledR}$, com vaporizador calibrado para Isofluorano), em circuito aberto, mantidas com máscara por quinze minutos.

Durante a duração do procedimento anestésico as aves foram monitoradas e tiveram a frequência cardíaca e respiratória aferidas, bem como a temperatura corporal. Após a realização da última mensuração da pressão intraocular o anestésico inalatório era fechado e as aves encaminhadas para a recuperação anestésica. Na recuperação anestésica as aves tinham a temperatura aferida e só foram transferidas para os recintos após completa recuperação, quando elas já conseguiam ficar em pé, a fim de evitar possíveis acidentes nos recintos ou complicações decorrentes da anestesia.

\section{4- AVALIAÇÃO OFTÁLMICA}

Os animais foram submetidos à inspeção da superfície ocular por meio de biomicroscopia por lâmpada em fenda ${ }^{11}$. Seguiram-se a aferição do $\operatorname{TLS}^{2}$, a tonometria de rebote ${ }^{3}$, a mensuração do comprimento da rima horizontal das pálpebras com paquímetro digital e o swab córneo-conjuntival para análise microbiológica (Fig.1). Todos os parâmetros oftálmicos foram coletados pelo

\footnotetext{
${ }^{11}$ Kowa-SL®; Kowa, Tóquio, Japão.

2 Teste Lacrimal de Shirmer®, Ophthalmos Fórmulas, São Paulo, SP, Brasil.

3 Tonômetro Tonovet®; EUA
} 
mesmo investigador, a fim de se evitarem alterações nos resultados. Apenas a tonometria basal, nas araras, foi realizada cinco minutos antes da realização do TLS.

Os testes supracitados seguiram a seguinte ordem nas araras: 1 . Tonometria de rebote; 2 . Anestesia geral; 3. Teste lacrimal de Schirmer olho direito (OD) e olho esquerdo (OE) respectivamente; 4. Swab corneoconjuntival; 5. mensuração da fissura palpebral; 6. Tonometria de rebote quinze minutos após mensuração inicial. Nos papagaios os testes oftálmicos seguiram a imediata sequência: 1. Tonometria de rebote; 2. Teste lacrimal de Schirmer Modificado (TLSm); 3. Mensuração da fissura palpebral. Para ambas as espécies os testes só foram realizados após inspeção ocular através de biomicroscopia com lâmpada em fenda.

\section{5- TESTE LACRIMAL DE SCHIRMER}

Uma vez atingido o plano anestésico, as araras foram posicionadas em decúbito lateral direito e posteriormente esquerdo para realização do TLS. As tiras do TLS foram inseridas no fundo do saco conjuntival da pálpebra inferior de ambos os olhos (Figura 1A) permanecendo por um minuto. Após um minuto a fita foi removida e o valor umectante da fita foi registrado.

Para a realização do TLS nos papagaios, as tiras padronizadas de TLS, tiveram que ser adaptadas. Para a confecção das fitas modificadas, as tiras padronizadas foram cortadas ao meio, reduzindo o diâmetro da fita de 5,00 mm para 2,5mm (SILVA, et al., 2013). As fitas modificadas de TLS (TLSm) foram inseridas no fundo do saco conjuntival da pálpebra inferior de olho direito (Figura 1B) e posteriormente no olho esquerdo, permanecendo por 1 minuto, após esse período sendo removido a leitura da fita realizada e anotada. 


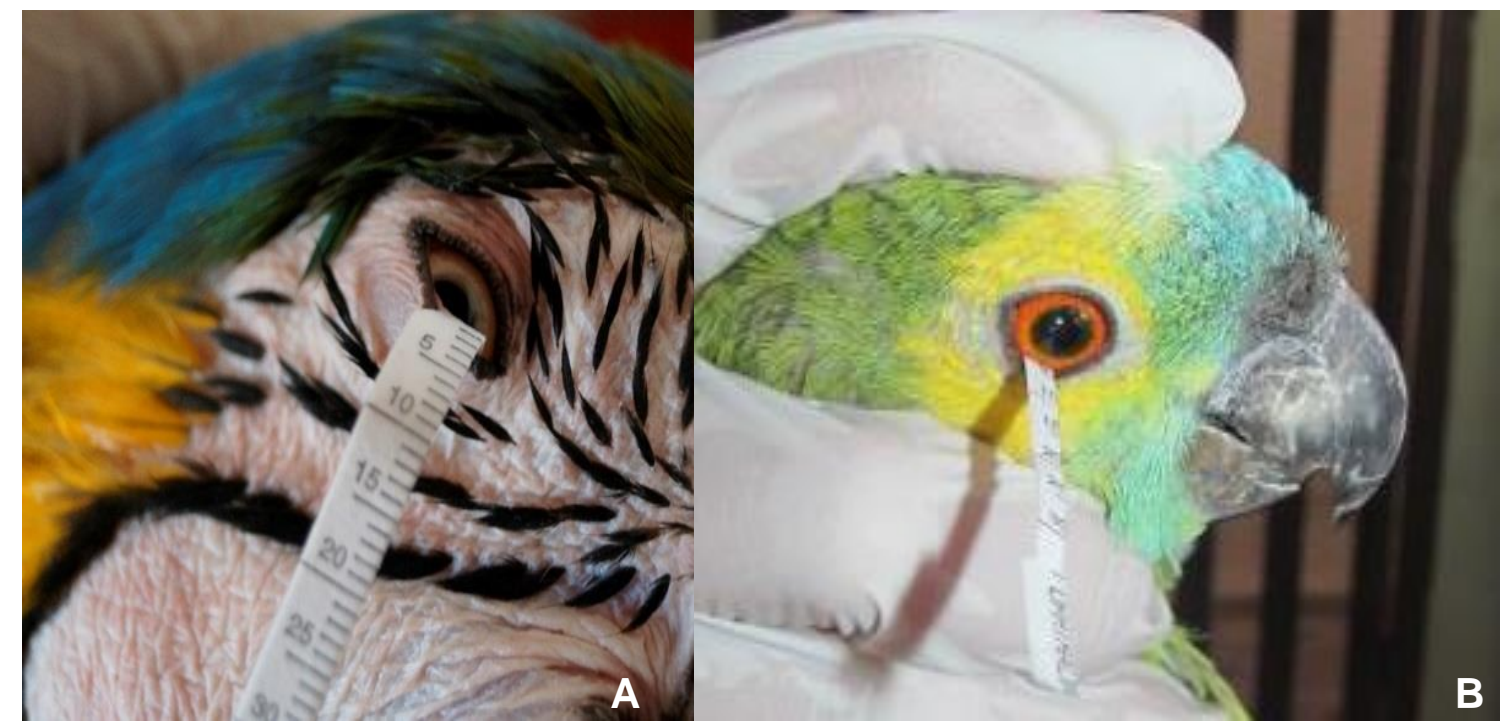

Figura 1- Fita do TLS e TLSm inserida no terço médio do saco conjuntival da pálpebra inferior do olho direito de Ara ararauna (A) e Amazona aestiva (B).

\subsection{TONOMETRIA}

Para a realização da tonometria, ambas as espécies foram fisicamente contidas em posição vertical, posicionando-se os dedos atrás da cabeça e sobre o bico para a aferição da PIO por meio da tonometria de rebote (PIO basal) (Figura 2). Como o tonômetro de rebote não possui ainda calibração para aves, optou-se nesse estudo usar a calibração para cães. Atenção especial foi dada a fim de ser evitar pressão excessiva na região cervical, para prevenir alterações iatrogênicas da PIO. Nas araras, uma nova mensuração da PIO foi realizada quinze minutos após a indução e manutenção anestésica. Para a segunda mensuração realizada apenas nas araras as aves foram mantidas na mesma posição da mensuração basal da PIO (Figura 2A). 


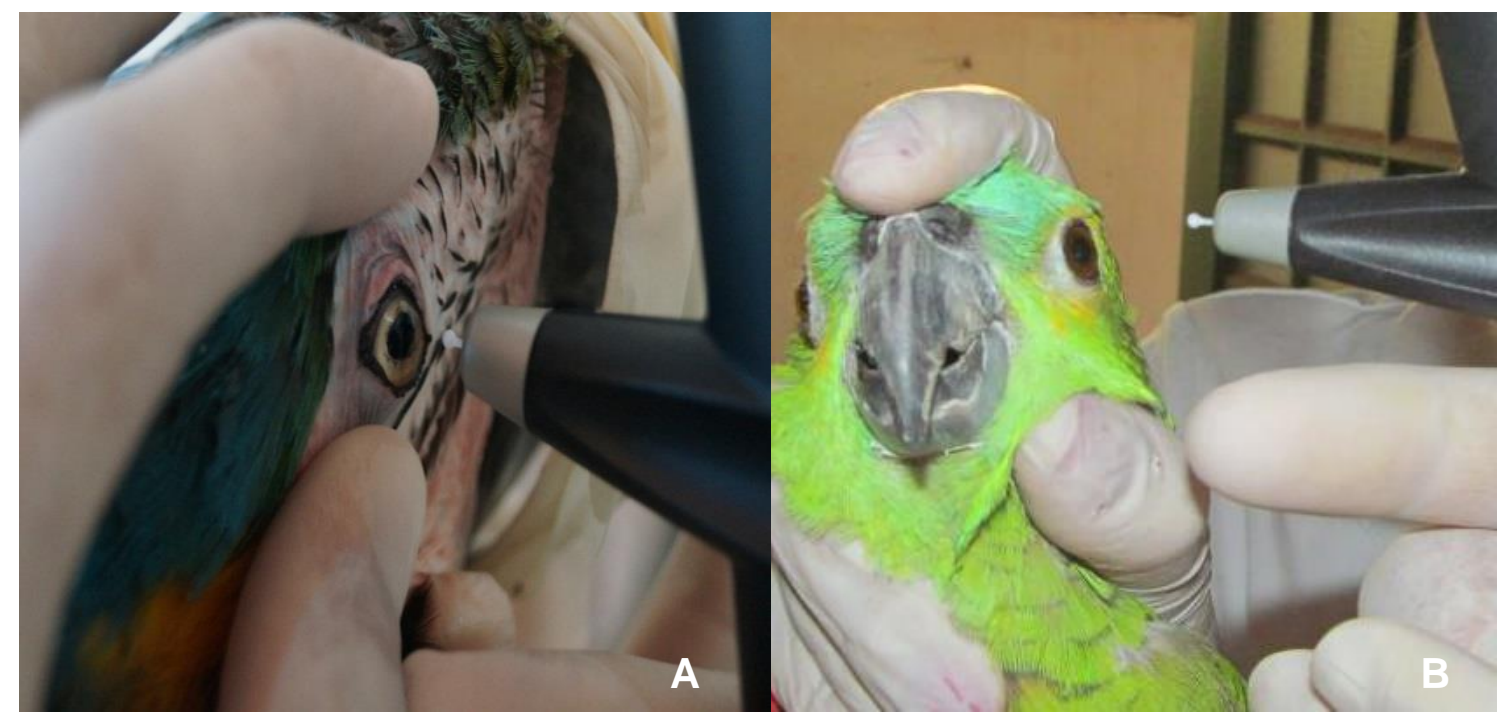

Figura 2- Tonometria de rebote olho direito de Ara ararauna (A) e olho esquerdo de Amazona aestiva (B).

\subsection{MENSURAÇÃO DO COMPRIMENTO DA FISSURA PALPEBRAL}

Utilizando-se paquímetro digital, aferiu-se o comprimento horizontal da rima palpebral, da comissura lateral a medial, sendo as pálpebras mantidas fechadas durante a mensuração (Figura 3).

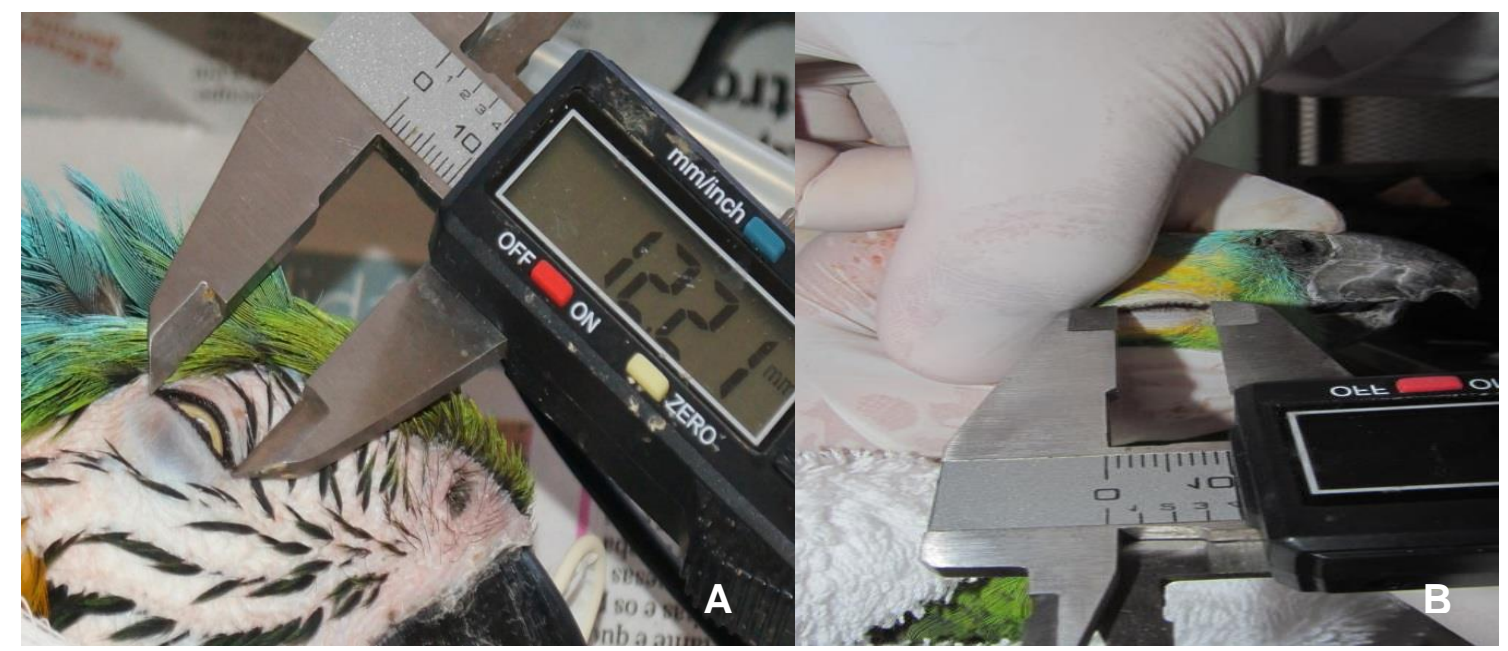

Figura 3 - Mensuração da fissura palpebral em olho direito de Ara ararauna (A) e de Amazona aestiva (B) com uso de paquímetro digital. 


\section{8- ANÁLISE MICROBIOLÓGICA}

Para a coleta microbiológica cotonetes de algodão hidrófilo estéril foram pressionados e mantidos diretamente e levemente contra o fundo do saco conjuntival inferior de ambos os olhos das araras (Fig.4). Após coleta o swab foi acondicionado em meio de Stuart e o material encaminhado ao Laboratório de Microbiologia do Hospital Veterinário da Universidade de Brasília. A cultura dos microorganismos foi realizada em placas de Petri com agar sangue incubadas a $37^{\circ} \mathrm{C}$ num ambiente aeróbico, durante 24 a $48 \mathrm{~h}$.

Após crescimento, as colônias foram identificadas com base na presença ou ausência de hemólise em ágar de sangue e as características morfológicas e bioquímicas de acordo com técnicas laboratoriais de rotina. Identificou-se a presença ou não de leveduras e fungos. .

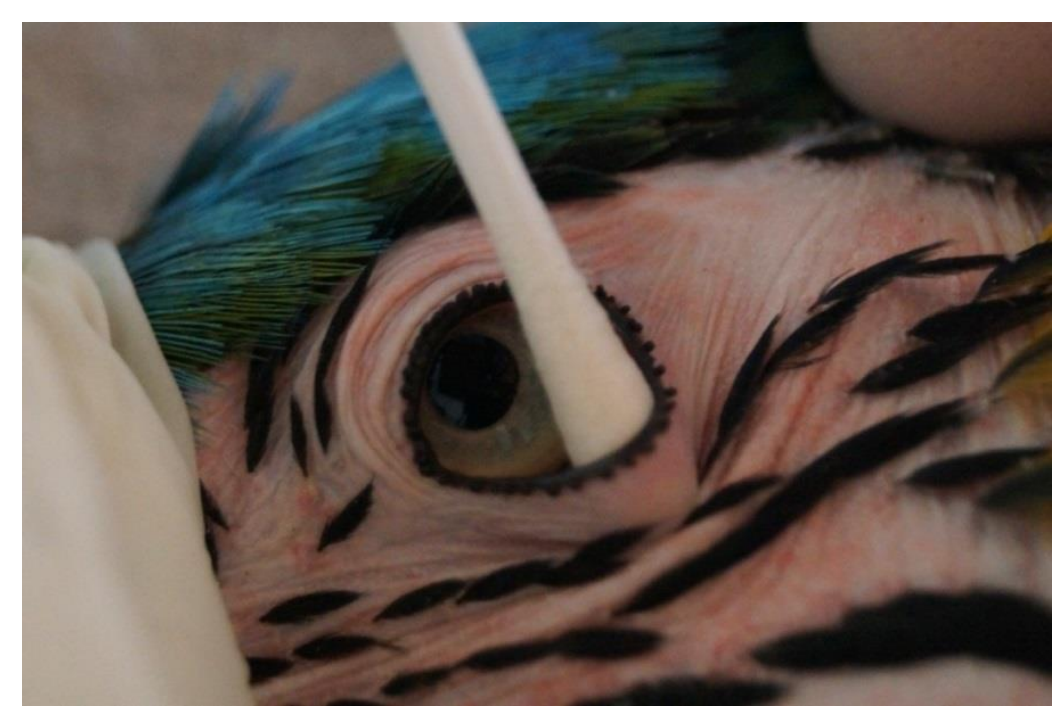

Figura 4 - Coleta de amostra para cultura microbiológica realizadacom auxílio de swab na região corneoconjun tival de olho esquerdo de uma Ara ararauna. 


\section{9- ANÁLISE ESTASTÍSTICA}

A análise estatística foi realizada com o software de computador disponível comercialmente (R CORE TEAM, 2014. R: A languange and environment for statistical computing. R Foundation for statistical, computing, Vienna, Austria). Os valores obtidos para PIO das araras foram comparados entre OD e OE pelo teste não paramétrico de Wilcox, porque uma distribuição normal não foi estabelecida, provavelmente por terem sido incluídos valores extremos. Os resultados foram reconhecidos como com diferenças significativas quando $P \leq 0,05$.

Para análise do TLS e a paquimetria das araras e dos papagaios, utilizou-se um teste $\mathrm{T}$ pareado, bem como para avaliação da PIO dos papagaios. Os resultados foram reconhecidos como com diferenças significativas quando $P \leq 0,05$. $O$ OD e $O E$ foram considerados como medidas independentes e avaliou-se se havia correlação da influência da paquimetria sobre a medição TLS e PIO pelo teste de Correlação de Pearson, com OD e OE considerados como medições independentes. Os resultados foram reconhecidos como com diferenças significativas quando $P$ $\leq 0,05$. 


\section{4-RESULTADOS}

Os valores médios encontrados para o TLS nas araras foram de 7,65 \pm 4,57 OD e de 6,57 $\pm 4,37 \mathrm{~mm} / \mathrm{min}$ OE e do TLSm nos papagaios de 6,37 $\pm 3,8$ $\mathrm{mm} / \mathrm{min}$ OD e de 6,50 \pm 4,3 mm/min OE,. Quando analisados dentro da mesma espécie, os valores obtidos para olho direito e esquerdo não apresentaram diferença estatística significativa, o mesmo sendo observado na avaliação da fissura palpebral de ambas as espécies estudadas, cujos valores médios foram de 11,67 \pm 0,078 $\mathrm{mm}$ OD e de 11,78 \pm 0,095 $\mathrm{mm}$ OE e 10,09 \pm 1,02 mm OD e OE $10,17 \pm 0,79$ para araras e papagaios, respectivamente (Tabela 1 e Tabela 2).

Em relação às medidas da pressão intraocular encontradas nas araras, os valores encontrados para OD de 11,34 $\pm 2,53$ e de 11,65 \pm 1,78 para OE não apresentaram diferença estatística entre eles, nem antes nem após a anestesia. Contudo, verificou-se diferença estatística significativa quando comparados os valores da PIO anteriormente a anestesia e os resultados encontrados sob anestesia quinze minutos após a PIO inicial. Essa diferença foi observada em ambos os olhos. Nos papagaios a tonometria de rebote para OD apresentou valor médio de 6,31 $\pm 1,7$ e para $O E 6,13 \pm 1,97$, não apresentando diferença estatística entre os olhos avaliados (Tabela 2). 
Tabela 1- Valores do Teste Lacrimal de Schirmer, da Pressão Intraocular (PIO) antes e após anestesia e da fissura palpebral realizados em Ara ararauna e expresso em média \pm desvio padrão.

\begin{tabular}{|c|c|c|c|c|}
\hline & $\begin{array}{c}\text { TLS } \\
\text { Araras }\end{array}$ & PIO Araras & $\begin{array}{c}\text { PIO Araras } \\
\text { Anestesiadas }\end{array}$ & $\begin{array}{c}\text { Fissura } \\
\text { palpebral nas } \\
\text { Araras. }\end{array}$ \\
\hline OD & $\begin{array}{c}7,65 \pm 4,57 \\
\mathrm{~mm} / \mathrm{min}\end{array}$ & $\begin{array}{c}11,34 \pm 2,53 \\
\mathrm{mmHg}\end{array}$ & $\begin{array}{c}7,65 \pm 2,37 \\
\mathrm{mmHg}\end{array}$ & $11,67 \pm 0,078 \mathrm{~mm}$ \\
\hline OE & $\begin{array}{c}6,57 \pm 4,37 \\
\mathrm{~mm} / \mathrm{min}\end{array}$ & $\begin{array}{c}11,65 \pm 1,78 \\
\mathrm{mmHg}\end{array}$ & $\begin{array}{c}7,77 \pm \\
1,78 \mathrm{mmHg}\end{array}$ & $11,78 \pm 0,095 \mathrm{~mm}$ \\
\hline
\end{tabular}

Tabela 2- Valores do Teste Lacrimal de Schirmer, da Pressão Intraocular (PIO) e da fissura palpebral realizados em Amazona aestiva e expresso em média \pm desvio padrão.

\begin{tabular}{cccc}
\hline & TLSm Papagaio & PIO Papagaio & $\begin{array}{c}\text { Fissura palpebral } \\
\text { nos Papagaios }\end{array}$ \\
\hline & & & \\
OD & $6,37 \pm 3,8 \mathrm{~mm} / \mathrm{min}$ & $6,31 \pm 1,7 \mathrm{mmHg}$ & $10,09 \pm 1,02 \mathrm{~mm}$ \\
OE & $6,50 \pm 4,3 \mathrm{~mm} / \mathrm{min}$ & $6,13 \pm 1,97$ & $10,17 \pm 0,79 \mathrm{~mm}$ \\
& & $\mathrm{mmHg}$ & \\
& & & \\
\hline
\end{tabular}

À análise das amostras microbiológicas realizadas, apenas dos olhos das araras, observaram-se amostras positivas para $84 \%$ dos olhos e 15\% não apresentaram crescimento de microrganismo. As amostras positivas apresentaram crescimento de microrganismo misto incluindo bactérias gram positivas e negativas, além de fungos e leveduras. A bactéria gram positiva mais isolada foi o Bacillus, spp.,presentes em 21, 93\% das amostras e a gram 
negativa a E.coli isolada em $20,72 \%$. Os fungos representaram $10,98 \%$ das amostras e as leveduras $17 \%$.

Tabela 3- Frequência de microrganismos isolados em setenta olhos de Ara ararauna clinicamente e oftalmologicamente saudáveis.

Microrganismos Isolados Frequência de Microrganismos Isolados

Ausência de Crescimento

$15,9 \%$

Bacteriano

\section{Gram Positivas}

Bacillus spp

$22 \%$

Staphylococcus aureus

$6,1 \%$

Staphylococcus spp

$20.7 \%$

Sreptococcus pyogenes

$1,2 \%$

\section{Gram Negativas}

Escherichia coli

$6,1 \%$

Fungos

$11 \%$

Leveduras

$17,10 \%$

Total

$100 \%$ 


\section{5- DISCUSSÃO}

A capacidade visual das aves pode influenciar diretamente o seu comportamento e esta diretamente relacionada a características reprodutivas, de voo e de alimentação (HART, 2002; BURTON, 2008). Essa necessidade de um sistema visual eficiente adaptado a situações diversas promove diferenciações anatômicas importantes. São observadas particularidades como a posição dos bulbos oculares na órbita, a proporção entre segmento anterior e posterior, que influenciarão o eixo e a acuidade visual (MARTIN, 2007). Peculiaridades anatômicas e funcionais levam a alterações no poder de acomodação visual e possíveis diferenças fisiológicas que poderão influenciar diretamente a avaliação e os valores de testes oftalmológicos (KERN; COLITZ, 2013).

Williams (2012) descreve que o uso da avaliação lacrimal por meio do TLS em aves apresenta dificuldades na execução devido ao tamanho dos olhos encontrados em relação ao da fita padronizada $(5 \mathrm{~mm})$ normalmente utilizada. Refere ainda que o uso da fita modificada (cortada à metade com 2,5 $\mathrm{mm}$ ) é uma opção viável, mas que esse procedimento dificultaria a interpretação dos resultados por falta de parâmetros de comparação. Em nosso estudo, por meio de um estudo piloto realizado com duas araras (total de quatro olhos) e dois papagaios (total de quatro olhos), observamos e avaliamos se haveria cooperação das aves com o referido teste.

Verificou-se que nas araras, apesar da fita ser encaixada com facilidade, elas não permitiram a mensuração lacrimal, demonstrando vocalização e agitação excessivas após a introdução da fita no saco conjuntival da pálpebra inferior. Ato contínuo, visibilizou-se movimentação constante da membrana nictitante, até remoção completa do teste, o que fazia com que a fita não permanecesse o tempo necessário para aferição, corroborando com o relatado por Williams (2012). Diante do exposto, a fim de minimizar o estresse oriundo da contenção física e fazer com que fosse possível a mensuração do TLS, optamos por realizar o TLS imediatamente após as araras serem submetidas à 
indução anestésica e atingirem o plano anestésico por meio de anestesia geral inalatória com isofluorano.

Em um estudo realizado por Korbel \& Leitenstorfer (1998) com 255 aves, de 42 espécies diferentes, valores do TLS foram descritos para psitaciformes com a utilização das fitas padrão de $5 \mathrm{~mm}(3,2 \pm 2,7 \mathrm{~mm} / \mathrm{min}$ TLS I e de 7,5 \pm $2,6 \mathrm{~mm} / \mathrm{min}$ TLS II); em psitaciformes utilizando a fita modificada com $4 \mathrm{~mm}$ ( $1,7 \pm 1,4$ para TLS I e de $4,5 \pm 2,8 \mathrm{~mm} / \mathrm{min}$ ); em falconiformes com a fita de 5 $\mathrm{mm}(2,0 \pm 1,7 \mathrm{~mm} / \mathrm{min}$ TLS I e de 4,2 $\pm 3,1$ TLS II) e em Accipitriformes com a fita de $5 \mathrm{~mm}(10.7 \pm 4 \mathrm{~mm} / \mathrm{min}$ TLS I e de $11,5 \pm 5,4 \mathrm{~mm} / \mathrm{min})$. Os resultados encontrados em nosso estudo para Ara ararauna são próximos aos descrito para psitacídeos realizados com o TLS tipo II, ou seja, com uso de anestésico local, mas superiores aos valores descritos para o TLS do tipo I.

Apesar do TLS ter sido realizado, imediatamente, após indução anestésica, não se pode descartar a influência do fármaco anestésico sobre os resultados obtidos, uma vez que os fármacos anestésicos levam a uma diminuição da produção lacrimal (GIROLAMO; SELLERI, 2013). Entretanto, alguns testes clínicos e oftálmicos são facilitados nessa espécie pela contenção anestésica. Como se buscou mimetizar a situação real em que o teste será realizado na rotina de atendimento em aves, acreditamos que os valores obtidos podem ser utilizados como padrão de normalidade para o TLS tipo I nessa espécie, seguindo-se a metodologia descrita. Ressalta-se que a amostra estudada apresentou homogeneidade fenotípica, e com um número significativo de animais para esta espécie, reforçando a confiabilidade do resultado.

Três araras apresentaram valores do TLS igual à zero, sendo que em uma delas esse valor foi observado em ambos os olhos. Como as aves estudadas apresentavam higidez clínica e oftálmica e como na literatura relatos de casos de ceratoconjuntivite em aves são raramente documentados (BARSOTTI, et al., 2013) acreditamos que tais valores possam estar relacionados à influência da anestesia ou uma variação individual. Embora erros metodológicos sempre devam ser considerados, a execução do TLS é de baixa complexidade, e foi realizado por profissional capacitado, que torna esta explicação menos plausível. 
Em aves a principal causa de diminuição na produção lacrimal é neurogênica, relacionada a traumas e não à síndrome de olho seco, diferentemente do que ocorre em cães (BARSOTTI, et al., 2013). Um recente estudo em cães demonstrou que a duração e tipo de agente inalatório promove uma redução da produção lacrimal, que só retorna ao valor basal normal em torno de 10 horas após a anestesia (SHEPARD, et al., 2011; MEEKINS, et al., 2015). Como as aves tinham um curto período de anestesia, não acreditamos que ela seja o único fator relacionado à ausência de umidificação da tira de Schirmer. Como os valores encontrados para arara $(7,11 \mathrm{~mm} / \mathrm{min})$ são inferiores aos descritos em cães $(15-25 \mathrm{~mm} / \mathrm{min}$ ) (SILVA, et al, 2013), o potencial de influência anestésica pode ser maior sobre a produção lacrimal na referida espécie do que em cães. Ressalta-se, ainda, que particularidades anatômicas como a posição da glândula lacrimal e de Harder, que são mais próximas do sistema de drenagem nasolacrimal possam ter correlação com a ausência da umidificação da tira nestes animais.

Em corujas, valores do teste lacrimal de Schirmer baixos são descritos e correlacionados com uma glândula lacrimal orbital pequena ou até mesmo ausente (HARRIS, et al., 2008). Portanto, estabelecer um teste padrão para avaliação lacrimal em aves pode ser difícil, devido às amplas diferenças anatômicas e fisiológicas dos aparatos de produção e de drenagem lacrimal entre as espécies (SMITH, et al., 2015).

Nos papagaios, mediante o estudo piloto que foi realizado, observou-se dificuldade na colocação da fita padrão do TLS no saco conjuntival da pálpebra inferior. Mesmo havendo inserção da fita no saco conjuntival, e colaboração inicial das aves, elas não permitiam que a fita permanecesse o tempo necessário para mensuração lacrimal, provavelmente pelo desconforto causado pelo tamanho padrão do teste.

Observamos que a utilização nos papagaios do TLSm, conforme descrito previamente (SILVA et al., 2013), foi melhor tolerado, sem causar estresse excessivo nas aves. Embora factível em aves com olhos maiores, como as araras, o TLS tem encontrado restrições em olhos pequenos (WILLIS; WILKIE, 1999; MULLER; MAULER; EULE, 2010; BECKWITH-COHEN, et al., 2015), o 
que nos também foi observado no presente estudo (da SILVA et al 2013; LANGE et al., 2012).

A fita de TLSm também foi utilizada por Meekins, et al. (2015) em olhos de flamingo. Os autores descreveram dificuldades na execução do teste mesmo utilizando a fita modificada, com valores superiores (12.3 $\pm 4,5$ $\mathrm{mm} / \mathrm{min}$ ) aos encontrados nos papagaios. Essa diferença pode ser justificada pelo tamanho da fita utilizada, uma vez que seguimos a metodologia descrita por da Silva, et al (2013) e Meekins, et al. (2015) utilizaram a descrita por Korbel; Leitensfore (1998). Além do tamanho da tira ser diferente, ela foi inserida no terço médio da pálpebra inferior e Meekins, et al. (2015) inseriram a fita para o canto temporal, com auxílio de um fórceps palpebral. Modificações metodológicas certamente interferem nos resultados encontrados e devem ser levados em consideração na interpretação dos mesmos, além das características anatômicas e fisiológicas.

Uma opção para minimizar a interferência metodológica ou até mesmo qualquer imprecisão na fabricação da fita (SOMMA, et al., 2015), seria a fabricação comercial de fitas modificadas padronizadas, permitindo a comparação dos dados encontrados. Outras variáveis podem interferir nos resultados obtidos como a habilidade do examinador, o local de inserção da tira dentro do saco conjuntival e capacidade de absorção das fitas de papel. $\mathrm{Na}$ tentativa de se minimizarem tais influências, os testes foram sempre realizados pelo mesmo examinador e em uma posição padronizada e com uma única marca de fita (GHAFFARI, et al., 2011).

Dadas as dificuldades descritas para o uso da fita do TLS (WILLIS; WILKIE, 1999; MULLER; MAULER; EULE, 2010; BECKWITH-COHEN, et al., 2015) ou mesmo dela modificada (WILLIAMS, 2012; KERN;COLITZ; 2013; MEEKINS, et al. 2015; SOMMA, et al. 2015), muitos autores sugerem o uso do teste do vermelho fenol. A literatura reporta que o teste do fenol é bem tolerado pelas aves, requer menor tempo de contenção, minimizando o estresse destes animais (BLISS, et al., 2015). Todavia, ele não mensura a lágrima basal e reflexa, apenas a residual (MEEKINS, et. al.,2015; GHAFFARI, et al., 2011; TROST, et al., 2007), e tem-se reportado baixa reprodutibilidade dos dados resultantes deste teste (STOUREY, et al., 2009). 
Stourey, et al.(2009) descreveram valores de TLS para 24 exemplares de Amazona ventralis parrots de 7,9 $\pm 2,6$ (TLS tipo 1) e valores de $5.1 \pm 3.3$ $\mathrm{mm} / \mathrm{min}$ para o TLS tipo II, valores acima e abaixo do encontrado na pesquisa em Amazona aestiva. Porém, a metodologia empregada não permite a comparação fiel dos dados.

Para mensuração da PIO, ambas as aves foram contidas fisicamente, na posição cervical, com os dedos atrás da cabeça e sobre o bico. O tonômetro de rebote (KERN; COLITZ, 2013) foi posicionado paralelo ao bulbo ocular e as medidas foram então realizadas. Todas as aves do estudo toleraram a mensuração da PIO sem a necessidade de anestesia geral ou contenção vigorosa. Evitou-se o uso de pressão excessiva na região cervical, para que não fossem induzidas alterações bruscas no retorno venoso e consequente aumento da PIO de forma iatrogênica (PAULI, et al., 2006).

Diversos estudos sobre a PIO foram conduzidos em aves com o tonômetro de aplanação, o Tonopen (REUTER, et al., 2010), como corujas (valores médios de $11 \pm 1.9)$ (HARRIS, et al., 2008), aves de vida livre (10,6 \pm $1.5 \mathrm{~mm} \mathrm{Hg})$, aves de rapina $(18,7 \pm 1.5$ e $11-16 \mathrm{~mm} \mathrm{Hg})$, em perus $(25 \mathrm{~mm} / \mathrm{Hg})$ e em psitacídeos 20-25 mmHg (BAYÓN; ALAMERA; TALAVERA, 2007). Apesar de ser um tonômetro amplamente utilizado na rotina veterinária, possui limitações quando empregado em olhos pequenos ou com espessura corneana pequena, limitando o seu uso (WILLIAMS, 2012), como verificado em nosso estudo piloto.

O tonômetro de rebote foi projetado para uso em animais com olhos pequenos, e tem sido utilizado recentemente em aves, como em Haliaeetus leucocephalus (21,5 $\pm 1,7 \mathrm{~mm} \mathrm{Hg}$ ) (KUHN, et al., 2013), Megascops asio (11 \pm $1,9 \mathrm{~mm} \mathrm{Hg}$ ) (HARRIS, et al., 2008), para Spheniscus dermersus $(31,77 \pm 3,3$ $\mathrm{mm} \mathrm{Hg}$ ) (GONZALEZ-ALONSO-ALEGRE, et al., 2015), Bubo bubo (10,45 \pm $1.64 \mathrm{~mm} \mathrm{Hg}$ ) (JEONG, et al., 2007) e em Phoenicopterus ruber ruber $(9,5 \pm 1,7$ $\mathrm{mm} \mathrm{Hg}$ ) (MEEKINS, et al., 2015). Entretanto, até o momento a literatura não reporta mensuração da PIO por meio da tonometria de rebote em Ara ararauna e Amazona aestiva.

O tonômetro de rebote possui uma curva de calibração interna para cães, equinos e felinos (RUSANEN, et al., 2010). Apesar do tonômetro de 
rebote ter sido projetado para animais, o mesmo não possui uma curva de calibração interna específica para mensurações em aves (JEONG, et al., 2007), e optou-se por utilizar a calibração para cães (HARRIS, 2008; MULLER; MAULER; EULE, 2010).

Pesquisadores compararam a acurácia e a reprodutibilidade do Tonovet ${ }^{\circledR}$ por meio do uso de um manômetro (um método invasivo de avaliação da PIO), concluindo serem os valores encontrados espécie dependente, podendo os dados estar subestimados ou superestimados, conforme a espécie (REUTER, et al., 2010). Porém, como a pesquisa foi conduzida em olhos enucleados, não se considerou a influência dos componentes ósseos e cartilaginosos dos processos esclerais, que nas aves particularmente apresentam relativa rigidez. Na opinião de Reuter, et al., (2010), essas estruturas não repercutem alterações importantes nos resultados das mensurações. Infere-se que os ossículos esclerais auxiliem na manutenção do formato do bulbo ocular, dando maior resistência e minimizando as influências das pressões externas e internas sobre o olho, repercutindo diretamente no valor da PIO.

Em Ara ararauna os ossos esclerais apresentam variações em relação a outros psitacídeos em quantidade, possuindo entre 12 e 13 ossículos (LIMA, et al., 2009) e o formato da órbita aberto, além de um osso zigomático menor (MACHADO, et al., 2006). Em papagaios a órbita é fechada e o número de ossículos é de 11-12 (LIMA, et al., 2009). Provavelmente, quanto menor a rigidez escleral sob o bulbo ocular, menores valores de pressão intraocular serão encontrados, uma vez que a pressão escleral excessiva pode influenciar demasiadamente a pressão intraocular como foi determinado em um estudo recente em cães, que avaliou a que a pressão demasiada sobre as pálpebras repercutia no aumento da PIO (BROADWATER, et al., 2008).

A discrepância de valores descritos para as diferentes espécies de aves advém de diferenças anatômicas importantes, como tamanho dos bulbos oculares e espessura corneana, além do próprio círculo circadiano da PIO (KUHN, et al.,2013), reforçando a necessidade de estabelecimento de valores espécie específicos, sem que se faça extrapolação de uma espécie a outra, como verificado entre araras e papagaios, ambos psitacídeos. 
Apesar das araras terem tolerado bem a realização da tonometria de rebote, dada à vocalização excessiva, estresse pela contenção física e próprio temperamento agitado da Ara ararauna, comprovado no estudo piloto, (SMITH et. al., 2015), optou-se por manipular e realizar os demais testes nesta espécie mediante contenção anestésica o que nos permitiu avaliar também a influência direta da anestesia sobre a PIO.

Os anestésicos inalatórios são os descritos como de eleição para aves, dada a sua segurança e por permitirem uma indução e uma recuperação anestésica rápida. Dos agentes inalatórios utilizados o isofluorano é o mais amplamente empregado (NICOLAU, et al.,2002; LICHTENBERGER; KO, 2007). As aves entraram em plano anestésico após a indução em média quatro minutos após a indução e foram mantidas anestesiadas com 3,5\% V. Todas as aves apresentaram boa recuperação após os quinze minutos anestesiadas, 0 que era uma preocupação, uma vez que as aves seriam reintroduzidas ao meio ambiente.

Os valores obtidos na segunda mensuração da PIO (15 minutos após a mensuração inicial e sob anestesia) demonstraram uma redução estatisticamente significativa da mesma, comparativamente aos valores basais. Os fármacos anestésicos podem levar à diminuição da PIO por facilitarem a drenagem do humor aquoso (MURPHY, 1985), por meio do relaxamento dos músculos extraoculares, supressão do sistema nervoso central e controle neurovascular da PIO (McMURPHY, et al., 2004). Pode-se inferir que também o estresse e a contenção exerçam alguma influencia neste mecanismo. Como existe uma íntima relação entres os músculos ciliares e a segunda via de drenagem do humor aquoso, a via não convencional, provavelmente esse relaxamento muscular proporcionado pela anestesia possa influenciar mais diretamente a PIO nas aves do que em outras espécies, apesar de estudos relatarem uma diminuição significativa da $\mathrm{PIO}$ em ratos anestesiados com isofluorano (DING, et a., 2012; JOHNSON; FAN; TORIS, 2008) e em galinhas após o uso de quetamina e xilazina (PRASHAR et al., 2007).

A mensuração da fissura palpebral revelou uma comissura palpebral maior para as araras em relação aos papagaios como o que é esperado, e o que justifica uma maior dificuldade na realização do TLS nos papagaios. Como 
descrito por alguns autores, olhos menores apresentam maior dificuldade na realização do TLS. Verificou-se, ainda, uma forte correlação positiva entre a fissura palpebral e o TLSm nos papagaios.

A microbiota conjuntival tem sido estudada em diferentes mamíferos e animais selvagens, a fim de direcionar a conduta terapêutica baseada em uma flora microbiológica presumida (MOORE \& NASISSE 1995). Em aves clinicamente normais, cerca de $83 \%$ dos agentes isolados são bactérias, sendo que em psitacídeos o Staphylococcus e Corynebacterium são predominantes (WILLIS; WILKIE, 1999; DUPONT, et al., 1994). Na presente pesquisa $84,15 \%$ das amostras analisadas apresentaram crescimento microbiológico, valor próximo ao descrito por Dupont, et al.( 1994). Entretanto, 56,1\% apresentaram crescimento bacteriano, número inferior ao descrito por WILLIS; WILKIE (1999), e similar ao encontrado por ZENOBLE, et al. (1983), com 59\% de crescimento bacteriano.

Os gêneros Staphylococcus spp e o Bacillus spp. foram os mais isolados, com $20,73 \%$ e $21,95 \%$ das amostras totais em olhos direito e esquerdo, respectivamente. Bacillus spp. são isolados comumente em repteis (SOMMA, et al., 2015) e em cães (ORIÁ, et al., 2014). Embora se tenha verificado maior prevalência de Gram positivas, corroborando com BAYÓN; TALAVERA (2007), a Escherichia coli representou 6,1\% da flora bacteriana observada, valor superior ao normalmente descrito, mas reportado como bactéri frequentemente isoladas em olhos de coruja (RODARTE - ALMEIDA, et al., 2013) e de flamingos (MEEKINS, et al., 2015). A presença de bactérias Gram-negativas é rara e representa cerca de 1\% das amostras normalmente analisadas para aves (BAYÓN; ALMELA; TALAVERA, 2007), diferentemente do reportado por GALERA, et al. (2002), que descreveram uma frequência maior de bactérias gram negativas em macacos- pregos.

Observou-se a presença de fungos e de leveduras em 11 e $17 \%$ das amostras, respectivamente, fato pouco relatado para aves (HOPPE, et al., 2000; DUPONT, et al., 1994), mas frequente em outras espécies como equinos (SGORBINI, et al., 2008). A presença de fungos pode ser de cunho transitório, decorrente do meio ambiente e da exposição, o que justifica sua baixa incidência, sendo mais isolados em bovinos e equinos, onde por sua vez o seu 
ambiente é mais rico em material orgânico (MEEKINS; ESHAR; RANKIN, 2014; SGORBINI, et al., 2008; HOPPES, et al.,2000; DUPONT, et al. 1994). As leveduras são isolados comuns de amostras fecais de aves e normalmente não estão associados com doenças clínicas, mas podem decorrer da contaminação local.

Verificou-se que a microbiota normal do saco conjuntival das araras é composta por um amplo espectro de microrganismos, incluindo bactérias, fungos e leveduras. Vale salientar que essa microbiota é influenciada pela estação do ano, localização geográfica, nutrição, densidade populacional e contatos com outros animais (ORIÁ, et al., 2015), o que torna importante ter uma demonstração da flora local de acordo com a região.

O conhecimento dos aspectos oculares normais específicos para cada espécie, bem como dos valores de referência de testes diagnósticos são essenciais para oftalmologia veterinária comparativa (BLISS, et al., 2015).

Mediante a regularidade dos valores encontrados e o número de animais estudados para ambas as espécies, acredita-se que os resultados obtidos sejam utilizados como de referência para Ara ararauna e Amazona aestiva. 


\section{6- CONCLUSÃO}

Este estudo estabeleceu valores de referência para testes oftálmicos para a Ara ararauna e para a Amazona aestiva, que certamente contribuirão para a diferenciação de valores fisiológicos e das afecções oculares, bem como para comparação de futuros estudos. 


\section{7- REFERÊNCIAS BIBLIOGRÁFICAS}

ABRAMS, George A. et al. Aspergillus Blepharitis and Dermatitis in a Peregrine Falcon-Gyrfalcon Hybrid ( Falco peregrinus $\times$ Falco rusticolus ). Journal Of Avian Medicine And Surgery, [s.I.], v. 15, n. 2, p.114-120, jun. 2001. Association of Avian Veterinarians (AAV).

AIZAWA, J. et al. Gross Anatomical Features of the Gastrointestinal Tract (GIT) of Blue and Yellow Macaws ( Ara ararauna ) - Oral Cavity and Pharynx. Anatomia, Histologia, Embryologia, [s.I.], v. 42, n. 6, p.420-424, 14 fev. 2013.

BARSOTTI, G., et al. Schirmer tear test type I readings and intraocular pressure values assessed by applanation tonometry (Tonopen ${ }^{\circledR} \mathrm{XL}$ ) in normal eyes of four European species of birds of prey. Vet Ophthalmol, [s.I.], v. 16, n. 5, p.365369, 23 nov. 2012. Wiley-Blackwell.

BAYÓN, A. et al. Avian ophthalmology. Eur. J. Companion Anim. Pract, v. 17, n. 3, p. 253-266, 2007.

BAYÓN, A.; ALMELA, R.M.; TALAVERA, J. Avian Ophthalmology. Ophthalmology, v.17, n.3, p.253-265, 2007.

BECKWITH-COHEN, Billie et al. Differences in ocular parameters between diurnal and nocturnal raptors. Vet Ophthalmol, [s.l.], v. 18, p.98-105, 18 nov. 2013. Wiley-Blackwell.

BIANCHI, C.A.C. Biologia Reprodutiva da Arara Canindé (Ara ararauna, Psittacidae) no Parque Nacional das Emas, GO. Dissertação (Mestrado em Ecologia) - Instituto de Biologia, Universidade de Brasília, Brasília. 1998. pp. 7 9, 17, 21. BIRDLIFE INTERNATIONAL. Species factsheet: Ara ararauna. 2014. 
$<$ http://www.birdlife.org/datazone/species/factsheet/22685539>, acesso em 12/08/2014.

BLISS, Cassandra D.; AQUINO, Susette; WOODHOUSE, Sarah. Ocular findings and reference values for selected ophthalmic diagnostic tests in the macaroni penguin (Eudyptes chrysolophus ) and southern rockhopper penguin ( Eudyptes chrysocome ). Vet Ophthalmol, [s.l.], v. 18, p.86-93, 18 nov. 2013. Wiley-Blackwell. DOI: 10.1111/vop.12123.

BROADWATER, Joshua J. et al. Effect of body position on intraocular pressure in dogs without glaucoma. American Journal Of Veterinary Research, [s.I.], v. 69, n. 4, p.527-530, abr. 2008. American Veterinary Medical Association (AVMA).

BROOKE, M. D. L.; HANLEY, S.; LAUGHLIN, S. B.. The scaling of eye size with body mass in birds. Proceedings Of The Royal Society B: Biological Sciences, [s.I.], v. 266, n. 1417, p.405-412, 22 fev. 1999.

BROOKS, Dennis E.. Avian cataracts. Seminars In Avian And Exotic Pet Medicine, [s.I.], v. 6, n. 3, p.131-137, jul. 1997. Elsevier BV. DOI: 10.1016/s1055-937x(97)80020-5

BURNS, R. B.; MAXWELL, M. H.. The structure of the Harderian and lacrimal gland ducts of the turkey, fowl and duck.: A light microscope study. J. Anat, [si], v. 128 , n. 2, p.285-292, out. 1979. Mensal.

BURTON, Richard F.. The scaling of eye size in adult birds: Relationship to brain, head and body sizes. Vision Research, [s.I.], v. 48, n. 22, p.2345-2351, out. 2008. Elsevier BV.

BUYUKMIHCl, Nedim C.; MURPHY, Christopher J.; SCHULZ, Terry. DEVELOPMENTAL OCULAR DISEASE OF RAPTORS.Journal Of Wildlife Diseases, [s.I.], v. 24, n. 2, p.207-213, abr. 1988. Wildlife Disease Association. 
DARWISH SMAH M. T.; EL-NAGA ,AMOURA M. ABOU; HUSSEIN, MOHAMED B. ; ATIA, INAS Y. H.. Some morphometric studies on the orbit of some different birds. Egypt. J. Exp. Biol. (Zoo.). 2006; 2(0): 241-256

DAVIDSON, Michael. Ocular consequences of trauma in raptors. Seminars In Avian And Exotic Pet Medicine, [s.I.], v. 6, n. 3, p.121-130, jul. 1997. Elsevier BV.

DAVIS, Kyshia et al. Comparative evaluation of aqueous humor viscosity. Vet Ophthalmol, [s.I.], v. 18, n. 1, p.50-58, 27 jan. 2014. Wiley-Blackwell.

DE STEFANO ME, MUGNAINI E: Fine structure of the choroidal coat of the avian eye. Vascularization, supporting tissue and innervation. Anat Embryol (Berl) 195:393-418, 1997

DING, CHUN; WANG, PING; TIAN, NING. Effect of general anesthetics on IOP in elevated IOP mouse model. Experimental Eye Research, [s.I.], v. 92, n. 6, p.512-520, jun. 2011. Elsevier BV.

DUPONT, C; CARRIER, M; HIGGINS, R. Bacterial and fungal flora in healthy eyes of birds of prey. Can Vet J., [si], v. 11, n. 35, p.699-701, nov. 1994.

FERNANDEZ, JULIA RODRIGUEZ-RAMOS; DUBIELZIG, RICHARD R.. Ocular and eyelid neoplasia in birds: 15 cases (1982-2011). Vet Ophthalmol, [s.I.], v. 18, p.113-118, 20 jan. 2014. Wiley-Blackwell.

FRANCISCO, L.R.; MOREIRA, N. Manejo, reprodução e conservação de psitacídeos brasileiros. Revista Brasileira de Reprodução Animal, Belo Horizonte, v.36, n.4, p.215-219, outubro/dezembro. 2012. Disponível em:

FRANZ-ODENDAAL, TAMARA A.. Intramembranous ossification of scleral ossicles in Chelydra serpentina. Zoology, [s.I.], v. 109, n. 1, p.75-81, fev. 2006. Elsevier BV. 
GALERA PD, AVILA MO, RIBEIRO $\mathrm{CR}$, et al. Estudo da microbiota da conjuntiva ocular de macacos-prego (Cebus apella) e macacos bugio 173 (Alouatta caraya) provenientes do reservatório de manso, MT, Brasil. Arquivos do Instituto Biológico. 2002; 69 (2): 33-36

GHAFFARI, MASOUD SELK et al. Intraocular pressure and Schirmer tear test results in clinically normal Long-Eared Hedgehogs (Hemiechinus auritus): reference values. Veterinary Ophthalmology, [s.I.], v. 15, n. 3, p.206-209, 31 out. 2011. Wiley-Blackwell.

GHAFFARI, MASOUD SELK et al. Reference values for intraocular pressure and Schirmer tear test in clinically normal Sanjabi sheep. Small Ruminant Research, [s.I.], v. 97, n. 1-3, p.101-103, maio 2011. Elsevier BV.

GIROLAMO, N. DI et al. Evaluation of intraocular pressure in conscious ferrets (Mustela putorius furo) by means of rebound tonometry and comparison with applanation tonometry. Veterinary Record, [s.I.], v. 172, n. 15, p.396-396, 13 mar. 2013. BMJ.

GODOY, S.N. Psittaciformes (Arara, Papagaio, Periquito). In: CUBAS, Z.S.; SILVA, J.C.R.; CATÃO-DIAS, J.L. Tratado de Animais Selvagens - Medicina Veterinária. 1ae edição. Editora Roca. São Paulo, 2007. pp. 222-224.

GONZALEZ-ALONSO-ALEGRE, ELISA M. et al. Central corneal thickness and intraocular pressure in captive black-footed penguins (Spheniscus dermersus). Vet Ophthalmol, [s.I.], v. 18, p.94-97, 10 set. 2014. WileyBlackwell.

GWYNE, J.A.; RIDGELY, R.S.; TUDOR, G.; ARGEL, M. Birds of Brazil - The Pantanal \& Cerrado of Central Brazil. $1^{\underline{a}}$ edição. Editora Horizonte. São Paulo, 2010. p. 114. 
HARRIS, M.c et al. Ophthalmic examination findings in a colony of Screech owls (Megascops asio). Veterinary Ophthalmology, [si], v. 3, n. 11, p.186-192, 2008.

HART, N.S. Vision in the peafowl (Aves: Pavo cristatus). The Journal of Experimental Biology. v.205, p.3925-3935, 2002.

HART, N.S.; PARTRIDGE, J.C.; CUTHILL, I.C. Retinal asymmetry in birds. Current Biology. v.10, n.2, p.115-117, 2002.

HIRSCH J. Falcon visual sensitivity to grating contrasts. Nature 300:57-58 (1982).

HOLMBERG, Bradford J.. Ophthalmology of Exotic Pets: SLATTER'S FUNDAMENTALS OF VETERINARY OPHTHALMOLOGY:. 4. ed. [si]: Saunders, 2008. 482 p.

HOLT, ELAINE; ROSENTHAL, KAREN; SHOFER, FRANCES S.. The phenol red thread tear test in large Psittaciformes. Vet Ophthalmol, [s.I.], v. 9, n. 2, p.109-113, mar. 2006. Wiley-Blackwell.

HOPPES, SHARMAN et al. Mycotic Keratitis in a Blue-fronted Amazon Parrot ( Amazona aestiva ). Journal Of Avian Medicine And Surgery, [s.I.], v. 14, n. 3, p.185-189, set. 2000. Association of Avian Veterinarians (AAV).

HVENEGAARD, ANA PAULA et al. Retrospective study of ocular disorders in Amazon parrots. Pesq. Vet. Bras., [s.I.], v. 29, n. 12, p.979-984, 2009.

JEONG, MAN-BOK et al. Comparison of the rebound tonometer (TonoVet ${ }^{\circledR}$ ) with the applanation tonometer (TonoPen XL ${ }^{\circledR}$ ) in normal Eurasian Eagle owls (Bubo bubo). Vet Ophthalmol, [s.I.], v. 10, n. 6, p.376-379, nov. 2007. WileyBlackwell.

JOHNSON, THOMAS V.; FAN, SHAN; TORIS, CAROL B.. Rebound Tonometry in Conscious, Conditioned Mice Avoids the Acute and Profound Effects of 
Anesthesia on Intraocular Pressure. Journal Of Ocular Pharmacology And Therapeutics, [s.I.], v. 24, n. 2, p.175-185, abr. 2008. Mary Ann Liebert Inc. JONES; MICHAEL P.; PIERCE, KENNETH E.; WARD, DANIEL. Avian Vision: A Review of Form and Function with Special Consideration to Birds of Prey. Journal Of Exotic Pet Medicine, [s.I.], v. 16, n. 2, p.69-87, abr. 2007. Elsevier BV.

KATO, KUMIKO. Comparison of two handheld applanation tonometers and the association of central corneal thickness, age, and intraocular pressure in normal and diseased canine eyes. Vet Ophthalmol, [s.I.], v. 17, n. 6, p.417-425, 12 fev. 2014. Wiley-Blackwell.

KERN TJ. Disorders of the special senses. In: Altman RB, Clubb SL, Dorrestein GM, Quesenberry K, eds. Avian Medicine and Surgery. Philadelphia, PA: WB Saunders; 1997:563-589

KERN, THOMAS J.; COLITZ, CARMEN M. H.. Exotic Animal Ophthalmology: Veterinary Ophthalmology: Two Volume Set. 5. ed. [si]: [si], 2013. 2260 p.

KERN, TJ, PAUL-MURPHY, J, MURPHY, CJ et al, Disorders of the third eyelid in birds: 17 cases. J Avian Med and Surgery. 1996;10:12-18.

KIM, JURY et al. IOP Change Undergoing Anesthesia in Rhesus Macaques (Macaca mulatta) with Laser-Induced Ocular Hypertension.Journal Of Veterinary Medical Science, [s.I.], v. 74, n. 10, p.1359-1361, 2012. Japanese Society of Veterinary Science.

KLEIN, HEIDI E. et al. Effect of eyelid manipulation and manual jugular compression on intraocular pressure measurement in dogs.Journal Of The American Veterinary Medical Association, [s.I.], v. 238, n. 10, p.1292-1295, 15 maio 2011. American Veterinary Medical Association (AVMA). 
KNOLLINGER, AMY M. et al. Evaluation of a rebound tonometer for measuring intraocular pressure in dogs and horses. Journal Of The American Veterinary Medical Association, [s.I.], v. 227, n. 2, p.244-248, jul. 2005. American Veterinary Medical Association (AVMA).

KORBEL R, LEITENSTORFER P. The modified Schirmer tear test in birds-a method for checking lacrimal gland function. Tierarztliche Praxis Ausgabe K, Kleintiere/Heimtiere 1998; 26: 284-294

KORBEL, R. Ocular manifestations of systemic diseases in birds. Tierärztl Praxis, v.20, n.4, p.385-394, 1992.

KORBEL, R. Practical lab: avian ophthalmology-principles and application. In: CONFERENCE ON AVIAN MEDICINE AND SURGERY, 2009, Hannover. Proceedings Association of Avian Veterinarians European Committee (EAAV), p.275-290.

KRAUTWALD-JUNGHANNS ME, KOSTKA VM, DORSCH B. Comparative studies on the diagnostic value of conventional radiography and computed tomography in evaluating the heads of psittacine and raptorial birds. J Avian Med Surg 1998;12:149-157.

KUHN, SONIA E. et al. Normal Ocular Parameters and Characterization of Ophthalmic Lesions in a Group of Captive Bald Eagles ( Haliaeetus leucocephalus ). Journal Of Avian Medicine And Surgery, [s.I.], v. 27, n. 2, p.90-98, jun. 2013. Association of Avian Veterinarians (AAV).

LABELLE, AMBER L. et al. Clinical utility of a complete diagnostic protocol for the ocular evaluation of free-living raptors. Veterinary Ophthalmology, [s.I.], v. 15, n. 1, p.5-17, 19 abr. 2011. Wiley-Blackwell.

LANGE, ROGÉRIO R.; LIMA, LEANDRO; MONTIANI-FERREIRA, FABIANO. Measurement of tear production in black-tufted marmosets ( Callithrix 
penicillata) using three different methods: modified Schirmer's I, phenol red thread and standardized endodontic absorbent paper points. Veterinary Ophthalmology, [s.I.], v. 15, n. 6, p.376-382, 20 fev. 2012. Wiley-Blackwell.

LICHTENBERGER, MARLA; KO, JEFF. Anesthesia and Analgesia for Small Mammals and Birds. Veterinary Clinics Of North America: Exotic Animal Practice, [s.I.], v. 10, n. 2, p.293-315, maio 2007. Elsevier BV.

LIMA, F.C.; VIEIRA, L.G.; SANTOS, A.L.Q.; DE SIMONE, S.B.S.;.HIRANO, L.Q.L.; SILVA, J.M.M.; ROMÃO, M.F. Anatomy of the scleral ossicles in brazilian birds. Brazilian Journal Morphology Science. v.26, n.3-4, p. 165-169, 2009.

LIMA, LEANDRO et al. Evaluation of standardized endodontic paper point tear test in New Zealand white rabbits and comparison between corneal sensitivity followed tear tests. Vet Ophthalmol, [s.l.], v. 18, p.119-124, 5 maio 2014. Wiley-Blackwell.

LYNCH, GWENDOLYN L.; HOFFMAN, ALLISON; BLOCKER, TIFFANY. Central corneal thickness in koi fish: effects of age, sex, body length, and corneal diameter. Vet Ophthalmol, [s.I.], v. 10, n. 4, p.211-215, jul. 2007. WileyBlackwell.

MACHADO, MARCELLO; SCHMIDT, ELIZABETH MOREIRA DOS SANTOS; MONTIANI-FERREIRA, FABIANO. Interspecies variation in orbital bone structure of psittaciform birds (with emphasis on Psittacidae). Vet Ophthalmol, [s.I.], v. 9, n. 3, p.191-194, maio 2006. Wiley-Blackwell.

MARTIN, G.r; SHAW, J.m. Bird collisions with power lines:Failing to see the way ahead? Biological Conservation, [si], p.2695-2702, 14 jul. 2010.

MCKIBBIN, MARTIN et al. Spectral domain optical coherence tomography imaging of the posterior segment of the eye in the retinal dysplasia and 
degeneration chicken, an animal model of inherited retinal degeneration. Vet Ophthalmol, [s.I.], v. 17, n. 2, p.113-119, 22 maio 2013. Wiley-Blackwell.

MCMURPHY, ROSE M.; DAVIDSON, HARRIET J.; HODGSON, DAVID S.. Effects of atracurium on intraocular pressure, eye position, and blood pressure in eucapnic and hypocapnic isoflurane-anesthetized dogs. American Journal Of Veterinary Research, [s.I.], v. 65, n. 2, p.179-182, fev. 2004. American Veterinary Medical Association (AVMA).

MEEKINS, JESSICA M. et al. Ophthalmic Diagnostic Tests and Ocular Findings in a Flock of Captive American Flamingos ( Phoenicopterus ruber ruber). Journal Of Avian Medicine And Surgery, [s.l.], v. 29, n. 2, p.95-105, jun. 2015. Association of Avian Veterinarians (AAV).

MEEKINS, JESSICA M.; ESHAR, DAVID; RANKIN, AMY J.. Tear production, intraocular pressure, and conjunctival bacterial flora in a group of captive blacktailed prairie dogs ( Cynomys ludovicianus ). Vet Ophthalmol, [s.I.], v. 18, p.132-136, 15 out. 2014. Wiley-Blackwell.

MERCADO, JULIO A. et al. Intraocular Pressure in Captive Black-footed Penguins (Spheniscus demersus) Measured by Rebound Tonometry. Journal Of Avian Medicine And Surgery, [s.I.], v. 24, n. 2, p.138-141, jun. 2010. Association of Avian Veterinarians (AAV).

MONTIANI-FERREIRA, Fabiano; MATTOS, Bianca Chaim; RUSS, Heloisa Helena Abil. Reference values for selected ophthalmic diagnostic tests of the ferret (Mustela putorius furo). Vet Ophthalmol,[s.I.], v. 9, n. 4, p.209-213, jul. 2006. Wiley-Blackwell.

MÜLLER, Kerstin; MAULER, Daniela Alice; EULE, Johanna Corinna. Reference values for selected ophthalmic diagnostic tests and clinical characteristics of chinchilla eyes (Chinchilla lanigera).Veterinary Ophthalmology, [s.I.], v. 13, p.2934, set. 2010. Wiley-Blackwell. DOI: 10.1111/j.1463-5224.2010.00801.x. 
MURPHY CJ, GLASSER A, HOWLAND HC: The anatomy of the ciliary region of the chicken eye. Invest Ophthalmol Vis Sci 36:889-896, 199522.

MURPHY CJ, KERN TJ, MCKEEVER K ET AL. Ocular lesions in free-living raptors. Journal of the American Veterinary Medical Association 1982; 181: 1302-1304.

MURPHY, C.J.; EVANS, H.E.; HOWLAND, H.C. Towards a schematic eye for the great horned owl. In: DUNKER, H. \& FLEISCHER, G. (Ed.) Functional morphology in vertebrates. New York: Gustav Fischer Verlag, 1985, p.703-706.

NAUTSCHER, NADINE et al. Comparative morphological evaluation of domestic animal cornea. Vet Ophthalmol, [s.I.], p.1-8, jul. 2015. WileyBlackwell.

NICOLAU, Alexandra Alves et al. O sevofluorano em psitacídeos (Amazonas aestiva): determinação da dose mínima (d. a. m) para produção de anestesia geral. Cienc. Rural, [s.I.], v. 32, n. 5, p.781-786, 2002. FapUNIFESP (SciELO). DOI: 10.1590/s0103-84782002000500007.

ORIÁ, Arianne P. et al. Ophthalmic diagnostic tests in captive red-footed tortoises ( Chelonoidis carbonaria ) in Salvador, northeast Brazil. Vet Ophthalmol, [s.I.], v. 18, p.46-52, 2 maio 2014. Wiley-Blackwell. DOI: 10.1111/vop.12175.

ORIÁ, Arianne P. et al. Ophthalmic diagnostic tests, orbital anatomy, and adnexal histology of the broad-snouted caiman ( Caiman latirostris ). Vet Ophthalmol, [s.I.], v. 18, p.30-39, 31 out. 2013. Wiley-Blackwell. DOI: 10.1111/vop.12115.

ORIÁ, Arianne P. et al. Tear production, intraocular pressure and conjunctival microbiota, cytology and histology of New Zealand rabbits (Oryctolagus cuniculus). Pesq. Vet. Bras., [s.I.], v. 34, n. 10, p.1024-1028, 2014. FapUNIFESP (SciELO). DOI: 10.1590/s0100-736x2014001000016. 
PARDUE MT, SIVAK JG: The functional anatomy of the ciliary muscle in four avian species. Brain Behav Evol 49:295-311, 199723.

PARDUE, M.T., ME. Andison, A. Glasser, and J.G. Sivak. 1996. Accommodation in Raptors. Inwst. @hthaL Vik Sci. 37: S725.

PAULI, Amy M. et al. Effects of the Application of Neck Pressure by a Collar or Harness on Intraocular Pressure in Dogs. Journal Of The American Animal Hospital Association, [s.I.], v. 42, n. 3, p.207-211, maio 2006. American Animal Hospital Association. DOI: 10.5326/0420207

PAUL-MURPHY, J.r. et al. PSITTACINE SKULL RADIOGRAPHY. Veterinary Radiology, [s.I.], v. 31, n. 3, p.125-131, 10 maio 1990. Wiley-Blackwell. DOI: 10.1111/j.1740-8261.1990.tb01850.x.

RAUSCHER, FRANZISKA GEORGIA, et al. Optical Coherence Tomography as a Diagnostic Tool for Retinal Pathologies in Avian Ophthalmology. Investigative Opthalmology \& Visual Science, [s.I.], v. 54, n. 13, p.8259-8269, 1 dez. 2013. Association for Research in Vision and Ophthalmology (ARVO).

REUTER, ANNE et al. Accuracy and reproducibility of the TonoVet $₫$ rebound tonometer in birds of prey. Veterinary Ophthalmology,[s.I.], v. 13, p.80-85, set. 2010. Wiley-Blackwell.

REUTER, Anne et al. Reference Intervals for Intraocular Pressure Measured by Rebound Tonometry in Ten Raptor Species and Factors Affecting the Intraocular Pressure. Journal Of Avian Medicine And Surgery, [s.I.], v. 25, n. 3, p.165172, set. 2011. Association of Avian Veterinarians (AAV).

RODARTE-ALMEIDA, Ana C.v. et al. O olho da coruja-orelhuda: observações morfológicas, biométricas e valores de referência para testes de diagnóstico oftálmico. Pesq. Vet. Bras., [s.I.], v. 33, n. 10, p.1275-1289, 2013. 
RUSANEN, Elina et al. Evaluation of a rebound tonometer (Tonovet ${ }^{\circledR}$ ) in clinically normal cat eyes. Veterinary Ophthalmology, [s.I.], v. 13, n. 1, p.3136, jan. 2010. Wiley-Blackwell.

SAMUELSON DON A. Ophthalmic Anatomy: Veterinary Ophthalmology: Two Volume Set. 5. ed. [si]: [si], 2013. 39 p.

SANTOS, Aa.; RAGUSA-NETTO, J.. Plant food resources exploited by Blueand-Yellow Macaws (Ara ararauna, Linnaeus 1758) at an urban area in Central Brazil. Braz. J. Biol., [s.I.], v. 74, n. 2, p.429-437, 2014.

SEDACCA, Kara; SAMUELSON, Don; LEWIS, Patricia. Examination of the anterior uveoscleral pathway in domestic species.Veterinary Ophthalmology, [s.I.], v. 15, p.1-7, 6 set. 2011. Wiley-Blackwell

SEIFERT, R.; JACOB M., JACOB, H.J. The avian prechordal head region: a morphological study. J. Anat., 183 (1993), pp. 75-89

SERUCA, Cristina et al. Ocular consequences of blunt trauma in two species of nocturnal raptors (Athene noctua and Otus scops).Veterinary Ophthalmology, [s.I.], v. 15, n. 4, p.236-244, 13 dez. 2011. Wiley-Blackwell.

SGORBINI, Micaela et al. Fungal Flora of Normal Eyes in Healthy Newborn Foals Living in the Same Stud Farm in Italy. Journal Of Equine Veterinary Science, [si], v. 9, n. 28, p.540-543, 2008.

SICK, H. Ornitologia Brasileira. Editora Nova Fronteira. Rio de Janeiro, 2001. pp. 351-368.

SILVA, Enry Garcia da et al. Tear production in canine neonates - evaluation using a modified Schirmer tear test. Veterinary Ophthalmology, [s.I.], v. 16, n. 3, p.175-179, 19 jul. 2012. Wiley-Blackwell. DOI: 10.1111/j.1463-5224.2012.01044.x.

SIMOVA-CURD, Stefka et al. Surgical Removal of a Retrobulbar Adenoma in an 
African Grey Parrot (Psittacus erithacus). Journal Of Avian Medicine And Surgery, [s.I.], v. 23, n. 1, p.24-28, maio 2009. Association of Avian Veterinarians (AAV). DOI: 10.1647/2008-008r.1.

SMITH, Stephen P.; BARBON, Alberto Rodriguez; FORBES, Neil A.. Evaluation of the Phenol Red Thread Tear Test in Falconiformes. Journal Of Avian Medicine And Surgery, [s.I.], v. 29, n. 1, p.25-29, mar. 2015. Association of Avian Veterinarians (AAV). DOI: 10.1647/2008-050.

SOMMA, André T. et al. The eye of the red-eared slider turtle: morphologic observations and reference values for selected ophthalmic diagnostic tests. Vet Ophthalmol, [s.I.], v. 18, p.61-70, 10 set. 2014. Wiley-Blackwell. DOI: 10.1111/vop.12213.

STOREY, E.S., CARBONI, D.A., KEARNEY,M.T.,TULLY,T.N. Use of phenol red thread tests to evaluate tear production in clinically normal amazon parrots and comparison with Schirmer tear test findings. JAVMA, vol. 235, No 10. Nov. 2009.

TROST, Katrin; SKALICKY, M.; NELL, Barbara. Schirmer tear test, phenol red thread tear test, eye blink frequency and corneal sensitivity in the guinea pig. Vet Ophthalmol, [s.I.], v. 10, n. 3, p.143-146, maio 2007. Wiley-Blackwell.

TSAI, S.S.; PARK, J.H.; HIRAI, K; ITAKURA, C. Eye lesions in pet birds. Avian Pathology, v. 22, n.1, p.95-112, 1993.

VON SPIESSEN, Lena et al. Clinical comparison of the TonoVet $®$ rebound tonometer and the Tono-Pen Vet $®$ applanation tonometer in dogs and cats with ocular disease: glaucoma or corneal pathology. Vet Ophthalmol, [s.I.], v. 18, n. 1, p.20-27, 17 out. 2013. Wiley-Blackwell.

WILLIAMS, David L.. Ophthalmology of Exotic Pets. [si]: [si], 2012. 248 p. 
WILLIS, A. Michelle; WILKIE, David A.. Avian Ophthalmology Part 1: Anatomy, Examination,. Journal Of Avian Medicine And Surgery,[si], v. 3, n. 13, p.160166, 1999.

WILLIS, A. Michelle; WILKIE, David A.. Avian Ophthalmology, Part 2: Review of Ophthalmic Diseases. Journal Of Avian Medicine And Surgery, [si], v. 4, n. 13, p.245-251, 1999.

WYGNANSKI-JAFFE, $T$ et al. Protective ocular mechanisms in woodpeckers. Eye, [s.I.], v. 21, n. 1, p.83-89, 18 nov. 2005. Nature Publishing Group.

ZENOBLE RD,; GRIFFITH RW,; SL, CLUBB. Survey of bacteriologic flora of conjunctiva and cornea in healthy psittacine birds. American Journal Of Veterinary Research, [si], v. 10, n. 44, p.1966-1967, 1983. 